OPEN ACCESS

Edited by:

Clara G. De Los Reyes-Gavilan, Consejo Superior de Investigaciones Cientificas (CSIC), Spain

Reviewed by:

Laetitia Aymeric,

INSERM U1232 Centre de Recherche en Cancérologie et Immunologie Nantes Angers (CRCINA), France

YiXu,

Texas A\&M Health Science Center. United States

*Correspondence: Annemarie Bolei Annemarie.Boleij@radboudumc.n

Specialty section:

This article was submitted to Microbiome in Health and Disease,

a section of the journal

Frontiers in Cellular

and Infection Microbiology

Received: 13 July 2021 Accepted: 04 October 2021 Published: 27 October 2021

Citation:

Taddese $R$, Roelofs $R$, Draper $D$ Wu X, Wu S, Swinkels DW, Tjalsma H and Boleij A (2021) Streptococcus gallolyticus Increases Expression and Activity of Aryl Hydrocarbon Receptor-

Dependent CYP1 Biotransformation Capacity in Colorectal Epithelial Cells. Front. Cell. Infect. Microbiol. 11:740704. doi: 10.3389/fcimb.2021.740704

\section{Streptococcus gallolyticus Increases Expression and Activity of Aryl Hydrocarbon Receptor-Dependent CYP1 Biotransformation Capacity in Colorectal Epithelial Cells}

Rahwa Taddese ${ }^{1}$, Rian Roelofs ${ }^{2}$, Derk Draper ${ }^{1}$, Xinqun $W_{u^{3}}$, Shaoguang $W u^{3}$, Dorine W. Swinkels ${ }^{2}$, Harold Tjalsma ${ }^{2}$ and Annemarie Boleij ${ }^{1 *}$

\footnotetext{
1 Department of Pathology, Nijmegen Institute for Molecular Life Sciences (RIMLS), Radboud University Medical Centre (Radboudumc), Nijmegen, Netherlands, ${ }^{2}$ Laboratory Medicine, Nijmegen Institute for Molecular Life Sciences (RIMLS), Radboud University Medical Centre (Radboudumc), Nijmegen, Netherlands, ${ }^{3}$ Department of Medicine, Division of Infectious Diseases, Johns Hopkins University, Baltimore, MD, United States
}

Objective: The opportunistic pathogen Streptococcus gallolyticus is one of the few intestinal bacteria that has been consistently linked to colorectal cancer (CRC). This study aimed to identify novel S. gallolyticus-induced pathways in colon epithelial cells that could further explain how S. gallolyticus contributes to CRC development.

Design and Results: Transcription profiling of in vitro cultured CRC cells that were exposed to $S$. gallolyticus revealed the specific induction of oxidoreductase pathways. Most prominently, CYP1A and ALDH1 genes that encode phase I biotransformation enzymes were responsible for the detoxification or bio-activation of toxic compounds. A common feature is that these enzymes are induced through the Aryl hydrocarbon receptor (AhR). Using the specific inhibitor $\mathrm{CH} 223191$, we showed that the induction of CYP1A was dependent on the AhR both in vitro using multiple CRC cell lines as in vivo using wild-type C57bl6 mice colonized with S. gallolyticus. Furthermore, we showed that CYP1 could also be induced by other intestinal bacteria and that a yet unidentified diffusible factor from the $S$. galloltyicus secretome (SGS) induces CYP1A enzyme activity in an AhR-dependent manner. Importantly, priming CRC cells with SGS increased the DNA damaging effect of the polycyclic aromatic hydrocarbon 3-methylcholanthrene.

Conclusion: This study shows that gut bacteria have the potential to modulate the expression of biotransformation pathways in colonic epithelial cells in an AhR-dependent manner. This offers a novel theory on the contribution of intestinal bacteria to the etiology of CRC by modifying the capacity of intestinal epithelial or (pre-)cancerous cells to (de)toxify dietary components, which could alter intestinal susceptibility to DNA damaging events.

Keywords: Streptococcus gallolyticus, colorectal cancer, gut microbiota, biotransformation, Aryl hydrocarbon (Ah) receptor 


\section{INTRODUCTION}

The resident gut microbiota is essential for human intestinal health and prevents the invasion of pathogens by providing colonization resistance and nutrient competition (Vollaard and Clasener, 1994; Hooper et al., 2002). The human epithelium itself wards of infections by the excretion of a continuous protective mucus layer and antimicrobials and by tightly sealing the paracellular space between adjacent cells (Matsuo et al., 1997; Chichlowski and Hale, 2008). However, in case of intestinal diseases such as inflammatory bowel disease (IBD) and colorectal cancer (CRC), these protective mechanisms are impaired, and the bowel wall becomes prone to bacterial infiltration, rendering the host more susceptible to opportunistic bacterial infections (Aksoy and Akinci, 2004; Stecher and Hardt, 2008).

One of the intestinal bacteria that has been consistently linked to human CRC is the opportunistic pathogen Streptococcus gallolyticus (previously known as Streptococcus bovis biotype I). Multiple studies have documented that $33 \%-100 \%$ of S. gallolyticus-infected patients have concomitant adenomas and carcinomas, which largely exceed the CRC rates reported in the general population (Lieberman et al., 2000; Corredoira et al., 2005; Boleij et al., 2011). Notably, nearly all of these patients did not present with gastrointestinal signs or symptoms, and the (pre-)cancerous lesions were thus solely detected based on the clinical infection with S. gallolyticus.

It is suggested that CRC or advanced adenomas provide a specific niche for S. gallolyticus. One of the described mechanisms is the collagen-binding ability of S. gallolyticus, which potentially contributes to the specific colonization of malignant colonic sites (Boleij et al., 2011). Furthermore, colonic tumor cell metabolites could facilitate the survival of S. gallolyticus, favoring its local outgrowth (Boleij et al., 2012). More recent insight shows specific increase in colonization in tumor-bearing mice, which is most likely due to an increase in the presence of secondary bile acids, resulting in the production of gallocin by $S$. gallolyticus reducing the presence of other enterococci, e.g., Enterococcus faecalis, and favoring its colonization (Aymeric et al., 2018; Pasquereau-Kotula et al., 2018). However, the specific binding to CRC tissue is controversial and debated. Although DNA-based approaches in three independent studies show S. gallolyticus colonization ranging from $0 \%$ to $2 \%$ in controls, $47 \%$ in normal tissue of cancer patients, and 3\%-74\% in tumor tissues (Abdulamir et al., 2010; Andres-Franch et al., 2017; Kumar et al., 2018), two other studies reported no significant difference between healthy and CRC patients (Boltin et al., 2015; Viljoen et al., 2015). In addition, no specific tumor cell enrichment was observed in tumor-bearing mice (Aymeric et al., 2018).

Although an incidental relationship between S. gallolyticus and CRC seems plausible, it still remains to be determined to which extent $S$. gallolyticus may also play a contributory role in the carcinogenesis process itself. It was already shown that the related bacterium Streptococcus infantarius strain NCTC8133 (now designated as Streptococcus equinus) increased the amount of aberrant crypt foci and adenomas in an azoxymethane (AOM)-induced rat model (Ellmerich et al., 2000) and increased COX-2 expression (Biarc et al., 2004). Similar results have been obtained for S. gallolyticus using an AOM-induced mouse model for CRC. This was corroborated by in vitro data that showed S. gallolyticus subsp. gallolyticus increases cell proliferation in HT29, HCT116, and LoVo cells, by increasing beta-catenin translocation to the nucleus and c-myc expression. Importantly, the latter was not observed with $S$. gallolyticus subsp. macedonicus and S. gallolyticus subsp. pasteurianus (Kumar et al., 2017). Our recent report shows that cell proliferation increase or decrease depends on the S. bovis substrain and the CRC cell lines employed (Taddese et al., 2020). This shows a complex relationship not only at strain level but also between CRC cells from different origin.

The aim of the current research was focused on the identification of S. gallolyticus subsp. gallolyticus-induced epithelial pathways that can, on the long-term, contribute to carcinogenesis. Our results show that a factor from S. galloltyicus that is also present in the S. gallolyticus secretome (SGS), induced cytochrome $\mathrm{P} 450$ (CYP)1 persistently through the Aryl hydrocarbon receptor (AhR) in four different colon adenocarcinoma cells. These expression data were confirmed in a mouse model, and subsequently, we show that SGS could increase the DNA damaging effect of the polycyclic aromatic hydrocarbon 3-methylcholanthrene in vitro. The AhR activation and CYP1 induction appeared to be $S$. bovis strain dependent and may potentially also be induced by other intestinal bacteria.

\section{MATERIALS AND METHODS}

\section{Cell Culture}

The colorectal adenocarcinoma cell lines (CRC cells) HT-29, SW480, HCT116, and Caco-2 (www.atcc.org) were cultured in Dulbecco's modified Eagle's medium (DMEM, Lonza) supplemented with $10 \%$ fetal calf serum (FCS), $20 \mathrm{mM}$ HEPES, $2 \mathrm{mM} \mathrm{L}$-glutamine, and $1 \times$ non-essential amino acids (Gibco) at $37^{\circ} \mathrm{C} / 5 \% \mathrm{CO}_{2}$. For gene-expression analysis, cells were serum starved to $1 \%$ FCS for $24 \mathrm{~h}$ before co-culturing with bacterial cells. These culturing conditions were used unless stated otherwise.

\section{Bacterial Strains}

The following Streptococcus bovis strains were used: S. gallolyticus subsp. gallolyticus strains UCN34 (Rusniok et al., 2010), NTB1 (Boleij et al., 2011), 1293, 1294 (Tripodi et al., 2005), and NTB12; Streptococcus infantarius NCTC8133 (Biarc et al., 2004) (NZ_LR594042.1); Streptococcus lutetiensis NTB2; S. gallolyticus subsp. macedonicus strains CIP105685T, 19AS, and ACA-DC205; and S. gallolyticus subsp. pasteurianus strains 992 and NTB7. A phylogenetic tree of these S. bovis strains was published in Taddese et al., 2020 (Taddese et al., 2020). Other bacterial strains were E. faecalis 19433 (www.atcc.org), Enterobacter cloacae NTB9, Staphylococcus lugdunensis NTB8, Salmonella typhimurium NTB6, Escherichia coli Nissle 1917, and E. coli NTB5 (Boleij et al., 2011). All strains were grown on Columbia blood agar or in brain heart infusion (BHI) broth 
(Difco) supplemented with $1 \%$ glucose at $37^{\circ} \mathrm{C} / 5 \% \mathrm{CO}_{2}$. E. coli was grown at 200 rounds per minute (rpm).

\section{Cell Proliferation Using MTT Assay}

For MTT assays, optimal cell seeding in 96-well plates (Greiner Bio-One, Austria) was defined at 5,000 cells/well for Caco-2, 1,500 cells/well for HCT116, 10,000 cells/well for HT29, and 6,000 cells/well for SW480 to allow for $72 \mathrm{~h}$ growth observation. Cells were incubated overnight to attach before addition of bacterial secretomes in a fourfold dilution in DMEM supplemented with $10 \%$ FCS. Secretomes were collected as follows. After culturing in $\mathrm{BHI}$ broth, bacteria were centrifuged at $4,700 \mathrm{rpm}$ for $20 \mathrm{~min}$ and filter sterilized using $0.2-\mu \mathrm{m}$ filters (Sigma-Aldrich, USA). Molecules larger than $10 \mathrm{kDa}$ were concentrated using Amicon ultra-15 centrifugal filters (Merck Millipore, Merck, USA). Concentrated secretomes were frozen at $-80^{\circ} \mathrm{C}$ until further use. MTT-assays were performed as described previously, and MTT assay was performed after 24, 48, and $72 \mathrm{~h}$. Metabolic activity of CRC cells measured by MTT assay was used as a measure for cell growth. All experiments were performed in quadruplicate. Area under the curve was calculated for each condition (strain) and compared to cells incubated with cell culture media containing BHI broth as control using independent sample t-test in GraphPad Prism 9.

\section{Microarray Analysis}

HT-29 cells were grown to confluence in T75 flasks and subsequently incubated with or without S. gallolyticus [multiplicity of infection (MOI) of 20] in two duplicate experiments. After $2 \mathrm{~h}$, the culture medium was refreshed, and incubation was prolonged for another $2 \mathrm{~h}$. This 4 -h incubation period was chosen for microarray analysis because induction of the COX-2 marker for chronic inflammation and CRC progression (Ellmerich et al., 2000) could be determined under these conditions. Next, HT-29 monolayers were washed three times with prewarmed PBS after which RNA was isolated according to the Qiagen protocol (Qiagen RNeasy kit) with on-column DNA digestion. RNA quantity was measured with Nano-drop (Thermo Scientific, USA), and RNA quality was checked with the Bio-analyzer 2000 (Agilent Technologies, USA). Samples with RNA integrity scores $\geq 9.0$ were approved for microarray analysis.

Gene expression profiling was performed using Affymetrix GeneChip Human Gene 1.0 ST arrays, representing all known human genes (Affymetrix Inc., Santa Clara, CA, USA). The Affymetrix GeneChip Whole Transcript Sense Target Labeling Assay was used to generate amplified and biotinylated sensestrands DNA targets from the entire expressed genome $(1.0 \mu \mathrm{g}$ of total RNA). The manufacturer's manual was followed for the hybridization, washing, and scanning steps (version $4, \mathrm{P} / \mathrm{N}$ 701880 Rev. 4). Arrays were hybridized by rotating them at $60 \mathrm{rpm}$ in the Affymetrix GeneChip hybridization oven at $45^{\circ} \mathrm{C}$ for $17 \mathrm{~h}$. After hybridization, the arrays were washed in the Affymetrix GeneChip Fluidics station FS 450. Arrays were scanned using the Affymetrix GeneChip scanner 3000 7G system.
The Affymetrix CEL files were first imported into Affymetrix Expression Console version 1.1 where control probes were extracted using the default robust multichip averaging (RMA) algorithm in order to perform quality analysis checks. The Area Under the Curve (AUC) of the Receiver Operator Characteristic was calculated using the positive and negative control probes. All arrays had an AUC score above the empirically defined threshold of 0.85 indicating a good separation of the positive controls from the negative controls.

Subsequently the CEL files were imported into Partek ${ }^{\circledR}$ (Partek ${ }^{\circledR}$ Genomic Suite software, version 6.4 Copyright ${ }^{\circledR} 2008$ Partek Inc., St. Louis, MO, USA) where only core exons were extracted and normalized using the RMA algorithm with GC background correction. Core transcript summaries were calculated using the mean intensities of the corresponding probesets. The correspondence of the replicate samples was confirmed using principle component analysis (PCA) and Pearson correlation analysis. After grouping the samples by cell type, an ANOVA was performed on the log2 intensities, and contrast $p$-values were calculated for all pair-wise comparisons between the sample groups. Genes with a fold change of at least 1.5 and a p-value below 0.05 were selected for further evaluation. Raw data files are deposited in the Gene Expression Omnibus (GEO) database, available through: http://www.ncbi.nlm.nih.gov/geo/query/acc.cgi?token= jtcvzsakgwaiibo\&acc=GSE29295.

\section{Quantitative Real-Time PCR}

For determination of CYP1A1 and ALDH1A3 gene expression in time-series experiments, CRC cell lines were incubated with S. gallolyticus (MOI, 20) for the indicated time periods. To determine concentration dependence and additive effects of 1 and $10 \mathrm{nM} 3$-methylcholanthrene (3MC; Sigma) on CYP gene expression, cells were incubated for $4 \mathrm{~h}$ with the indicated bacterial MOIs. To determine AhR-dependent CYP gene expression, CRC cells were incubated in the presence of the AhR-antagonist $\mathrm{CH}-223191(3 \mu \mathrm{M}$; Calbiochem) for $1 \mathrm{~h}$ and subsequently incubated with S. gallolyticus (MOI, 20) and/or $1 \mathrm{nM} 3 \mathrm{MC}$. These relatively low concentrations of $3 \mathrm{MC}$ ( 1 and $10 \mathrm{nM}$ ) were used to avoid saturation of CYP1A1 induction by $3 \mathrm{MC}$, which allowed to determine the additive effect of S. gallolyticus on CYP1A1 expression under these conditions. To determine the effect of bacteria-associated factors on CYP gene expression, S. gallolyticus, E. faecalis, or E. coli were cocultured with Caco-2 cells for $6 \mathrm{~h}$. Then, the supernatants were spun for $10 \mathrm{~min}$ at $4,000 \mathrm{~g}$ and subsequently passed through a $0.2-\mu \mathrm{m}$ filter to remove bacteria. Next, fresh serum-starved Caco-2 cells $(24 \mathrm{~h})$ were incubated with the secretomes for the indicated time periods. Caco-2 and HT-29 cells were incubated with the bacterial strains at a MOI of 20 for 2 and $4 \mathrm{~h}$ to determine the differences between CYP1A1 induction for the different $S$. bovis subspecies in comparison with the Gram-positive bacterium E. faecalis and the Gram-negative bacterium E. coli. The above-described interventions were all performed in at least two replicate experiments. CRC cells were disrupted in RLT-lysis buffer, and RNA was extracted according to the Qiagen protocol (RNeasy Mini-Kit). Next, Iscript Reverse 
Transcriptase PCR (Bio-Rad) was performed to synthesize $1 \mu \mathrm{g}$ of cDNA under the following conditions: $5 \mathrm{~min}$ at $25^{\circ} \mathrm{C}, 30 \mathrm{~min}$ at $42^{\circ} \mathrm{C}$, and $5 \mathrm{~min}$ at $85^{\circ} \mathrm{C}$. Expression of the genes listed in Supplementary Table $\mathbf{S 1}$ was compared to the expression of the household gene glyceraldehyde-3-phosphate dehydrogenase (GAPDH) (4310884E gene expression assay; Applied Biosystems) using the following quantitative real-time PCR (qPCR) protocol: 2 min at $50^{\circ} \mathrm{C}, 10 \mathrm{~min}$ at $95^{\circ} \mathrm{C}$, and 40 cycles of $15 \mathrm{~s}$ at $95^{\circ} \mathrm{C}$ and $60 \mathrm{~s}$ at $60^{\circ} \mathrm{C}$ (7900 HT, Applied Biosystems). All genes measured with custom primers (Biolegio) were analyzed with SYBR green Mastermix (Applied Biosystems), and all gene-expression assays were analyzed with Universal Mastermix (Applied Biosystems). The relative quantity (RQ) values were calculated via the $\Delta \Delta \mathrm{Ct}$ method (Pfaffl, 2001) using SDS 2.2.1 software. The log2 values of the $\Delta \Delta \mathrm{Ct}$ values were plotted on a linear scale, whereby the 0 level represents no expression change. For all data with two grouping variables, twoway ANOVAs were performed, and for data with one grouping variable, one-way ANOVA or Student's t-test were performed in GraphPad Prim 5. Differences were considered significant below pvalue of 0.05 .

\section{Western Blotting}

Expression of CYP1A1 was evaluated at the protein level in Caco- 2 cells, as these cells are best suited to measure CYP1A1 at the protein level (Meunier et al., 1995). However, it should be noted that also in this case, CYP1A1 levels are below the level of detection without addition of specific stimulating agents (Rosenberg and Leff, 1993). The experiments of this study were further challenged by the fact that only viable bacterium strongly stimulates CYP1A1, whereas prolonged coincubations with viable bacteria resulted in the death of Caco- 2 cells. To overcome these challenges, confluent Caco-2 monolayers were incubated with $1 \mu \mathrm{M} 3 \mathrm{MC}$ or cocultured with S. gallolyticus at a MOI of 50. The use of this high 3MC concentration and high MOI allowed a rapid and relatively strong induction of CYP1A1, while cellular damage by bacterial proliferation at $\leq 6 \mathrm{~h}$ time points was minimized. After $6 \mathrm{~h}$ of incubation, Caco- 2 cells were refreshed with medium containing $10 \mu \mathrm{g} / \mathrm{ml}$ chloramphenicol to block further bacterial growth for prolonged incubations. After 6 , 9 , and $12 \mathrm{~h}$ of incubation, cells were dislocated in PBS-EDTA and disrupted in lysis buffer (50 mM HEPES, $0.5 \mathrm{M} \mathrm{NaCl}, 1.5 \mathrm{mM}$ $\mathrm{MgCl}_{2}, 1 \mathrm{mM}$ EDTA, $10 \%$ glycerol, and 1\% Trition-X100) (Anwar-Mohamed and El-Kadi, 2009). As control of induction and to test several different CYP1A antibodies (Supplementary Information) Caco-2 cells were incubated with $1 \mu \mathrm{M} 3 \mathrm{MC}$ for $20 \mathrm{~h}$ or non-treated and subsequently lysed. Lysates were vortexed every $10 \mathrm{~min}$ during incubation on ice for $1 \mathrm{~h}$. Next, samples were spun at $12,000 \mathrm{~g}$ for $10 \mathrm{~min}$ and stored at $-20^{\circ} \mathrm{C}$ until further analysis. Fifty micrograms of protein in sodium dodecyl sulfate (SDS) sample buffer (50 mM Tris-HCl, pH 6.0, $2 \%$ SDS, $5 \% \beta$-mercaptoethanol, and $10 \%$ glycerol) was incubated for $5 \mathrm{~min}$ at $95^{\circ} \mathrm{C}$ prior to $12.5 \%$ glycine SDSpolyacrylamide gel electrophoresis (SDS-PAGE) (Towbin et al., 1979). Proteins were transferred to polyvinylidene fluoride (PVDF) membranes (Amersham) by Western blotting. Next, membranes were blocked for $1 \mathrm{~h}$ in $5 \%$ bovine serum albumin (BSA) in Tris-buffered saline supplemented with Tween 20
(0.1\%) (TBS-T) and incubated with monoclonal mouse antiCYP1A1 antibodies (Santa Cruz) diluted 1:500 in TBS-T, monoclonal mouse anti- $\beta$-actin antibody (Sigma A5441) diluted 1:25,000 in TBS-T, monoclonal mouse anti-CYP1A1/ $1 \mathrm{~A} 2$ antibodies (K06; collection of Dr. W. Peters) diluted 1:800 in TBS-T, or polyclonal rabbit anti-CYP1A1 antibody (Human Biologics Inc.) diluted 1:1,000 in 5\% BSA, or polyclonal rabbit anti CYP1A1/1A2 antibody (Human Biologics Inc.) diluted 1:800 in $5 \%$ BSA. Bound antibodies were visualized with the ECL detection system (Amersham) using antimouse immunoglobulin G (IgG) horseradish peroxidase (HRP) conjugates diluted 1:50,000 or antirabbit IgG HRP conjugates diluted 1:50,000 in 5\% milk in TBS-T (Jackson ImmunoResearch).

\section{7-Ethoxyresorufin-O-Deethylase Enzyme Activity Assay}

After incubation for 6, 9, and $12 \mathrm{~h}$, Caco-2 cells were washed with ice-cold PBS and lysed in $0.1 \mathrm{M}$ potassium phosphate buffer (0.1M dipotassium phosphate, 0.1M EDTA, and 20\% glycerol, $\mathrm{pH}$ 7.4). Note that viable bacteria were removed after the 6-h time point to avoid premature cell death by excessive bacterial proliferation as described in the previous section. Cells were disrupted by mechanical shearing on ice (crude cell lysates) and stored at $-80^{\circ} \mathrm{C}$ until use. Protein concentrations were determined with the Bradford protein assay following the manufacturers' description (BioRad). Crude cell lysates were diluted to $100 \mu \mathrm{g} / \mathrm{ml}$ protein in assay buffer (0.1M dipotassium phosphate and 0.1M EDTA, pH 7.4), and $4 \mu \mathrm{M}$ ethoxyresorufin (Molecular Probes) was added. Samples were prewarmed at $37^{\circ} \mathrm{C}$ before addition of $10 \mu \mathrm{M}$ reduced nicotinamide adenine dinucleotide phosphate (NADPH) (Sigma). The conversion of ethoxyresorufin (non-fluorescent) into resorufin (fluorescent) is catalyzed by CYP1A1 and requires the presence of NADPH. The reaction was started by the addition of NADPH and resorufin production in the samples was measured during a 10-min time period on a Shimadzu RF-5000 spectrofluorometer at an excitation of $550 \mathrm{~nm}$ and emission of $580 \mathrm{~nm}$. Known concentrations of resorufin (Molecular Probes) were used to create a calibration curve to calculate the amount of resorufin formed from ethoxyresorufin, catalyzed by the CYP1A1 enzyme (Yu et al., 2001). To compare individual samples, the amount of resorufin produced per minute was related to the protein concentration in the sample (resorufin/min.mg). The amount of resorufin produced per minute per milligram is a measure of the CYP1A1 activity in the sample. Two-way ANOVA statistics was used to determine significant changes.

\section{COMET Assay}

The additional effects of bacterial products on DNA damage by $0.1 \mu \mathrm{M} 3 \mathrm{MC}$ were measured using the COMET assay (Trevigen). Secretomes of S. gallolyticus, E. faecalis, and E. coli were incubated with Caco-2 cells in quadruplicate. After priming Caco- 2 cells for $6 \mathrm{~h}$ with these secretomes, $0.1 \mu \mathrm{M} 3 \mathrm{MC}$ was added, and incubation was prolonged for $18 \mathrm{~h}$. This relatively low concentration of $3 \mathrm{MC}$ was used to allow assessment of a possible additive effect of bacterial stimulation on $3 \mathrm{MC}$ toxicity. Higher 
concentrations could mask such an additive effect due to saturation of CYP1A1 induction by $3 \mathrm{MC}$ itself. $\mathrm{H}_{2} \mathrm{O}_{2}(100 \mu \mathrm{M})$ was used as positive control for DNA damage. After incubation of Caco-2 cells with the supernatants, $3 \mathrm{MC}$ or $\mathrm{H}_{2} \mathrm{O}_{2}$, cells were washed with warm PBS, harvested by trypsin treatment and spun at $200 \mathrm{~g}$ for $5 \mathrm{~min}$. Cells were counted, and 8,000 cells per condition were washed with Mg- and Ca-free ice-cold PBS. Next, cells were dissolved in low-melting agarose and mounted on COMET slides. After $30 \mathrm{~min}$ at $4^{\circ} \mathrm{C}$ in the dark to solidify the agarose, the immobilized cells were disrupted in Trevigen lysis solution for $60 \mathrm{~min}$ at $4^{\circ} \mathrm{C}$. After lyses of the cells in the solidified agarose, DNA was unwound by alkaline treatment $(\mathrm{pH}>13)$ for $30 \mathrm{~min}$. Subsequent electrophoresis for $30 \mathrm{~min}$ at $25 \mathrm{~V}$ was employed to yield migration of DNA in the agarose. In this assay, the migration distance of DNA is a measure of the amount of DNA damage under a certain condition. After electrophoresis, COMET slides were washed in $0.4 \mathrm{M}$ Tris- $\mathrm{HCl}(\mathrm{pH} 7.5)$ and fixed for $10 \mathrm{~min}$ in absolute alcohol. DNA damage (observed as COMET-like structures) was visualized by SYBRgreen staining and fluorescence microscopy (Leica). A total of 100 COMETs per condition were independently scored by two researchers that were uninformed about the experimental conditions, following the methodology of Collins et al. (Collins, 2004). DNA damage was calculated as reference to the positive $\mathrm{H}_{2} \mathrm{O}_{2}$ control. One-way ANOVA in GraphPad Prism 4.00 was performed to determine significance of the results $(\mathrm{p}<0.05)$.

\section{Mice Colonization With S. gallolyticus}

The mouse strains used in this study were C57bl6 purchased from Jackson Laboratory (Bar Harbor, ME, USA) or obtained as littermates of in-house breeding. We administered kanamycin $(1 \mathrm{~g} / \mathrm{L})$ and doxycyclin $(100 \mathrm{mg} / \mathrm{L})$ for 5 days in drinking water, followed by oral inoculation with the S. gallolyticus strain UCN34 $\left(\sim 5 \times 10^{7}\right.$ and $5 \times 10^{8}$ bacteria in PBS) or PBS alone (sham control) in mice at 4 weeks of age. Simultaneously with antibiotics pretreatment, mice were orally gavaged with the AhR-inhibitor CH223191 (10 $\mu \mathrm{g} / \mathrm{g} /$ day) dissolved in corn oil (vehicle) or with vehicle alone, continued until sacrifice at day 7 postinoculation of $S$. gallolyticus. Mice were randomly placed in groups, making sure that there was no cage effects for mice experiments. Sham mice were housed separately from S. gallolyticus colonized mice. We quantified fecal bacterial colonization as colony-forming units (CFUs) per gram stool on $\mathrm{BHI}$ agar supplemented with $5 \mu \mathrm{g} / \mathrm{ml}$ doxycyclin. Single colonies were boiled in $50 \mu \mathrm{ldH} 2 \mathrm{O}$, and S. gallolyticus colonization was confirmed with SodA PCR (SodA d1- CCTTATGCATATGA TGCTCTTGAGCC, SodA d2-AGATAGTAAGCGTGTTCCC AAACGTC, 488 bp product; DNA was denatured at $95^{\circ} \mathrm{C}$ for $10 \mathrm{~min}$ followed by 40 cycles at $94^{\circ} \mathrm{C}$ for $30 \mathrm{~s}, 56^{\circ} \mathrm{C}$ for $35 \mathrm{~s}$, and $72^{\circ} \mathrm{C}$ for $72 \mathrm{~s}$, and subsequent elongation for $7 \mathrm{~min}$ at $72^{\circ} \mathrm{C}$ ) (Poyart et al., 2002). At experimental time points, we harvested one piece each of the cecum in Trizol reagent for RNA analysis. qPCR was performed on RNA extracted from Trizol using TaqMan gene expression assays for CYP1A1 (Mm00487218_m1), IL4 (Mm00445259_m1), AhR (Mm00478932_m1), and PTGS2 (Mm00478374_m1) relative to 18s (4318839) and standard operation conditions on 7500 fast system (Applied Biosystems). The colons were Swiss rolled, paraffin embedded, and subsequently sectioned at $4 \mu \mathrm{m}$ for $\mathrm{H} \& \mathrm{E} /$ periodic acid-Schiff (PAS) staining or IHC ki67 analysis. Histology was reviewed by an expert GI pathologist. All mice were kept in specific pathogen-free (SPF) conditions prior to S. gallolyticus colonization in the Johns Hopkins University (JHU) animal facility. The mouse protocols were approved by the Johns Hopkins University Animal Care and Use Committee in accordance with the Association for Assessment and Accreditation of Laboratory Animal Care International.

\section{S. gallolyticus ELISA}

To measure serum response to $S$. gallolyticus, 96-well plates were coated with $50 \mu \mathrm{g} / \mathrm{ml}$ collagen IV from rat tail in $0.02 \mathrm{M}$ acetic acid for $1 \mathrm{~h}$. Plates were washed twice in PBS. Next, plates were coated with $1 \times 10^{9} \mathrm{~S}$. gallolyticus UCN34 per well o/n in PBS at $37^{\circ} \mathrm{C}$. Plates were fixed in $4 \%$ paraformaldehyde for $1 \mathrm{~h}$ at room temperature and stored at $4^{\circ} \mathrm{C}$ until further use. Wells were blocked with 3\% skim milk in PBS-0.5\% Tween-20 (PBS-T). Serum was diluted in 3\% skim milk in PBS-T 1:50 and incubated for $1.5 \mathrm{~h}$ at room temperature with gentle shaking. A serum-free control was used as reference together with non-infected mouse serum. Plates were washed four times in PBS-T for $5 \mathrm{~min}$ and subsequently incubated with antimouse-HRP in 3\% skim milk in PBS-T 1:5,000 for $1 \mathrm{~h}$ at room temperature. Plates were washed four times for $5 \mathrm{~min}$ in PBS-T and developed with $100 \mu \mathrm{TMB}$ substrate in 5-10 min. The reaction was stop with $50 \mu \mathrm{l} 2 \mathrm{~N}$ $\mathrm{H}_{2} \mathrm{SO}_{4}$. The $\mathrm{OD}$ was measured at $450 \mathrm{~nm}$ in a BioRad plate reader with reference filter at $655 \mathrm{~nm}$ within $30 \mathrm{~min}$ after stopping the reaction.

\section{RESULTS}

\section{Microarray Analysis Uncovers Induction of Host Oxidoreductase Gene Expression by S. gallolyticus}

To unravel the effects of S. gallolyticus on gene expression of CRC cells, a transcriptome analysis was performed $4 \mathrm{~h}$ after coculturing of S. gallolyticus UCN34 with HT29 CRC cells. Microarray analysis showed a total of 44 significantly differentially expressed genes upon S. gallolyticus exposure (Table 1), which was a surprisingly low number in comparison to about 150 differentially expressed genes upon coincubation with other non-pathogenic bacteria under the same conditions (GEO-GSE29295). Strikingly, as much as nine of these S. gallolyticus-regulated genes appeared to belong to oxidoreductase pathways (Table 1 in bold), including CYP1A1, $A D H 1 A$, and $A L D H 1 A 3$ (Supplementary Figure S1). For validation, 18 (out of 44) genes with normalized expression levels $>6$ on the used Affymetrix GeneChip were selected. The corresponding log-2 values for microarray and qPCR of 10 of these genes showed similar levels by both methods as predicted by Pearson correlation $(r=0.94 ; p<0.001)$ (Figures 1A, B). In line with microarray results, CYP1A1 (log $2 \mathrm{RQ}, 1.94)$ and 
TABLE 1 | Microarray analysis significantly differentially expressed genes in HT29 CRC cells.

\begin{tabular}{|c|c|c|}
\hline Reference & Gene & FC $(p<0.05)$ \\
\hline \multicolumn{3}{|c|}{ Upregulated genes } \\
\hline NM_000499 & Cytochrome P450, family 1, subfamily A, polypeptide 1 (CYP1A1) & 3.01 \\
\hline NM_007363 & Non-POU domain containing, octamer-binding (NONO) & 2.68 \\
\hline NM_016474 & Chromosome 3 open reading frame 19 (C3orf19) & 2.31 \\
\hline NM_000667 & Alcohol dehydrogenase 1A (ADH1A) & 2.25 \\
\hline NM_007260 & Lysophospholipase II (LYPLA2) & 1.99 \\
\hline NM_012399 & Phosphatidylinositol transfer protein, beta (PITPNB) & 1.82 \\
\hline NM_000693 & Aldehyde dehydrogenase 1 family, member A3 (ALDH1A3) & 1.77 \\
\hline NM_024409 & Natriuretic peptide C (NPPC) & 1.75 \\
\hline NM_013252 & C-type lectin domain family 5, member A (CLEC5A) & 1.54 \\
\hline NM_001083538 & POTE ankyrin domain family, member E (POTE2) & 1.54 \\
\hline NM_003079 & SWI/SNF related regulator of chromatin, member 1 (SMARCE1) & 1.5 \\
\hline NM_002308 & Lectin, galactoside-binding, soluble, 9 (LGALS9) & 1.48 \\
\hline NM_013289 & Killer cell immunoglobulin-like receptor (KIR3DL1) & 1.46 \\
\hline NM_002032 & Ferritin, heavy polypeptide 1 (FTH1) & 1.45 \\
\hline NM_004891 & Mitochondrial ribosomal protein L33 (MRPL33) & 1.45 \\
\hline NM_002755 & Mitogen-activated protein kinase kinase 1 (MAP2K1) & 1.44 \\
\hline NM_173359 & Eukaryotic translation initiation factor 4E family member 3 (EIF4E3) & 1.44 \\
\hline NM_182488 & Ubiquitin specific peptidase 12 (USP12) & 1.43 \\
\hline NM_005004 & NADH dehydrogenase (ubiquinone) 1 beta subcomplex, 8 (NDUFB8) & 1.42 \\
\hline NM_178433 & late cornified envelope 3B (LCE3B) & 1.42 \\
\hline NM_004255 & Cytochrome c oxidase subunit Va (COX5A) & 1.42 \\
\hline \multicolumn{3}{|c|}{ Downregulated genes } \\
\hline AF280797 & Ghrelin opposite strand RNA 2 (non-protein coding) (C3orf42) & 0.70 \\
\hline NM_052861 & Chromosome 4 open reading frame 42 (C4orf42) & 0.70 \\
\hline NM_144712 & Solute carrier family 23 (nucleobase transporters) (SLC23A3) & 0.69 \\
\hline NM_000437 & Platelet-activating factor acetyl hydrolase 2 (PAFAH2) & 0.69 \\
\hline BC090889 & AHNAK nucleoprotein 2 (AHNAK2) & 0.69 \\
\hline NM_001384 & DPH2 homolog (DPH2) & 0.69 \\
\hline NM_018373 & Synaptojanin 2 binding protein (SYNJ2BP) & 0.68 \\
\hline NM_002500 & Neurogenic differentiation 1 (NEUROD1) & 0.66 \\
\hline NM_006147 & Interferon regulatory factor 6 (IRF6) & 0.65 \\
\hline NM_000941 & P450 (cytochrome) oxidoreductase (POR) & 0.65 \\
\hline NM_001009955 & Single-stranded DNA binding protein 3 (SSNP3) & 0.64 \\
\hline NM_001930 & Deoxyhypusine synthase (DHPS) & 0.64 \\
\hline NM_005793 & Non-metastatic cells 6, protein (NME6) & 0.63 \\
\hline NM_015690 & Serine/threonine kinase 36 (STK36) & 0.63 \\
\hline NM_152289 & Zinc finger protein 561 (ZNF561) & 0.62 \\
\hline NM_015911 & Zinc finger protein 691 (ZNF691) & 0.62 \\
\hline NM_001005749 & Glucosidase, beta, acid (GBA) & 0.61 \\
\hline NM_007021 & Chromosome 10 open reading frame 10 (c10orf10) & 0.59 \\
\hline NM_024518 & UL16 binding protein 3 (ULBP3) & 0.59 \\
\hline NM_004417 & Dual specificity phosphatase 1 (DUSP1) & 0.57 \\
\hline NM_145238 & Zinc finger and SCAN domain containing 20 (ZSCAN20) & 0.53 \\
\hline NM_139169 & TruB pseudouridine (psi) synthase homolog 1 (TRUB1) & 0.48 \\
\hline NM_130900 & Retinoic acid early transcript 1L (RAET1L) & 0.43 \\
\hline
\end{tabular}

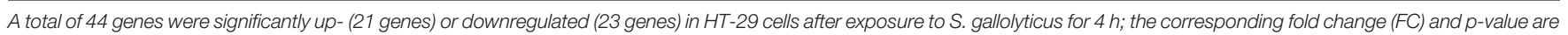
listed. Genes printed in bold belong to the oxidoreductase pathway as depicted in Supplementary Figure S1.

ALDH1A3 $(\log 2 \mathrm{RQ}, 1.02)$ were also found to be the most significant differentially expressed genes by qPCR (Figure 1 and Supplementary Figure S2). Taken together, these data imply that S. gallolyticus induces the expression of CYP1A1 and $A L D H 1 A 3$. Interestingly, the corresponding enzyme activities of these genes are involved in biotransformation of drugs and food components and are best known for their clearing function in the liver (Nebert and Dalton, 2006). As the expression of these enzymes is elevated during CRC progression (McKay et al., 1993; Ding and Kaminsky, 2003; Huang et al., 2009), and thereby could be related to colon carcinogenesis, we decided to further focus on these genes.

\section{S. gallolyticus-Induced Oxidoreductase Expression and Activity}

The temporal induction of CYP1A1 and ALDH1A3 expression was examined in the cell lines HT29, Caco-2, SW480, and HCT116 after exposure to $S$. gallolyticus. CYP1A1 was consistently upregulated $(\mathrm{p}<0.001$ ) in all cell lines upon 2,4 , and $6 \mathrm{~h}$ of coculturing with S. gallolyticus (Figure 2A). The induction of $A L D H 1 A 3$ was less evident among the different cell lines, although $A L D H 1 A 3$ was significantly increased to a $\log 2$ RQ between 1.1 for Caco-2 and 6.9 for HT-29 after 4 and 6 h (p < 0.001) (Figure 2B). Next, CYP1A1 induction was evaluated at the protein and functional level. To this purpose, Western blot analysis 


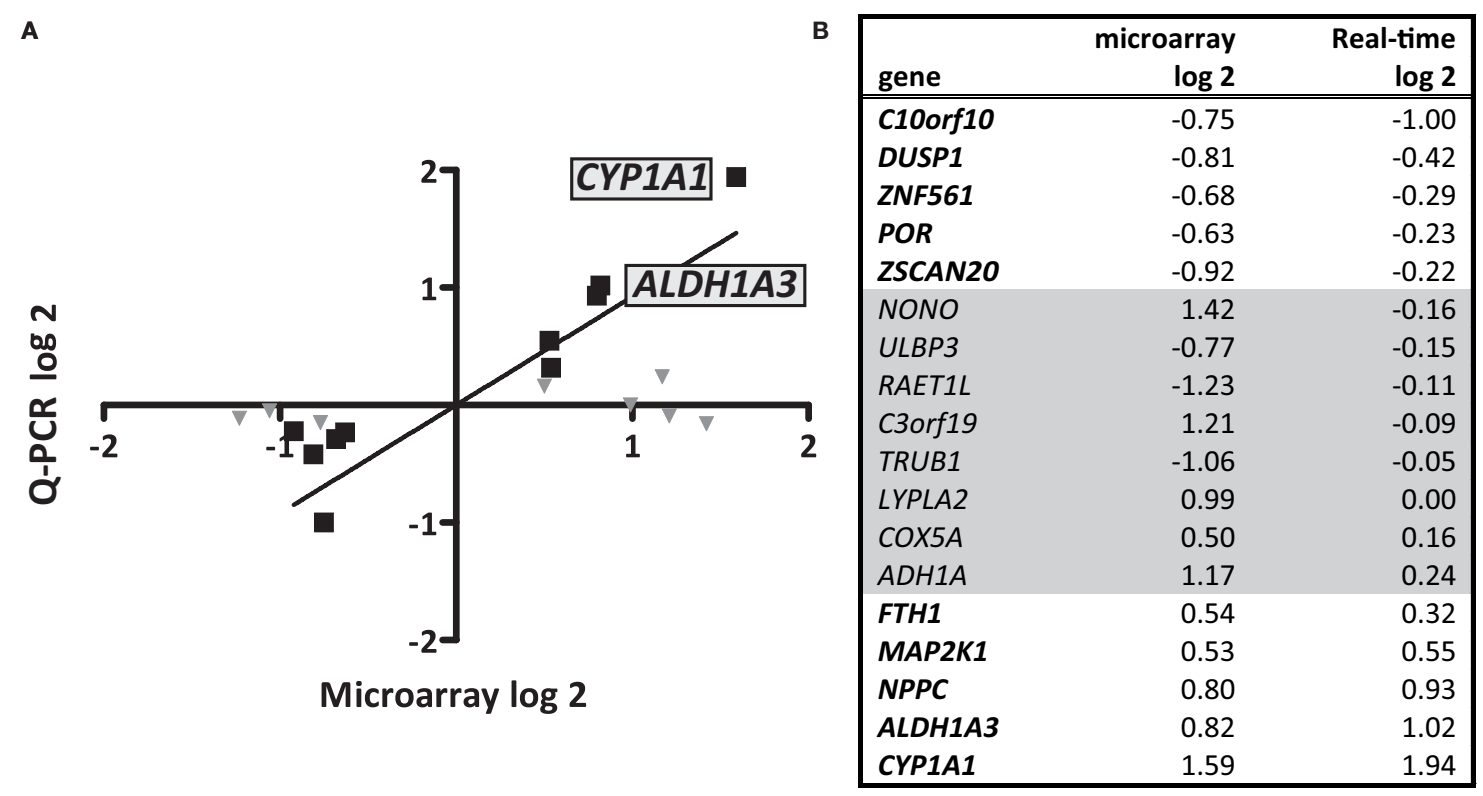

FIGURE 1 | Microarray data and validation. Microarray analysis was performed to profile S. gallolyticus UCN34-induced pathways that could be involved in CRC. (A) The upregulation of 18 selected genes was validated by quantitative real-time PCR (qPCR) analysis. The positions of the most significantly upregulated genes CYP1A1 and ALDH1A3 are indicated. (B) The corresponding log 2 values of microarray and qPCR are listed for each gene. The 10 genes that showed similar effects in microarray and qPCR [Pearson correlation ( $r=0.94 ; p<0.001)$ ] are (B) printed in bold and (A) marked by black squares. Gene expression changes that could not be validated by qPCR are $\mathbf{( B )}$ printed in gray and $(\mathbf{A})$ marked by gray triangles.

was performed on protein extracts from Caco-2 cells harvested at different time points after S. gallolyticus coincubation. Our initial experiments, and the results of others (Meunier et al., 1995), indicated that Caco- 2 cells were best suited to detect CYP1A1 at the protein level, and CYP1A1 is only detectably present after stimulation with inducing agents, such as 3-methylcholanthrene (3MC), with maximum protein expression levels after 18-20 h (Rosenberg and Leff, 1993). Because such long incubation times are not feasible with live S. gallolyticus, Caco-2 cells were stimulated with S. gallolyticus at a high MOI of 50 for $6 \mathrm{~h}$ to obtain a short but strong induction, after which bacteria were removed for prolonged incubations of 9 and $12 \mathrm{~h}$ (see Materials and Methods). 3MC was used in the same time course as a control for CYP1A1 induction in Caco-2 cells (Aboutabl et al., 2009), and human liver microsomes expressing CYP1A1 at high level were loaded as positive control on the Western blot. S. gallolyticus induced cellular CYP1A1 levels $(\sim 58 \mathrm{kDa})$ after 6 and $9 \mathrm{~h}$ compared to untreated Caco-2 cells (Figure 2C and Supplementary Figure S3), which was reduced to background levels after $12 \mathrm{~h}$. $3 \mathrm{MC}$ continued to increase CYP1A1 levels up to $12 \mathrm{~h}$ of stimulation. To validate these findings, CYP1A1 enzyme activity was determined in Caco- 2 by the 7 ethoxyresorufin-O-deethylase (7-EROD) assay that measures conversion of ethoxyresorufin into resorufin by functional CYP1A1 enzyme. Resorufin production was found to be significantly increased by S. gallolyticus after $6 \mathrm{~h}$ incubation $(\mathrm{p}<$ 0.05 ), while $3 \mathrm{MC}$ increased CYP1A1 activity at all three time points $(\mathrm{p}<0.001)$ (Figure 2D). Thus, these activity data corroborate the real-time and Western blot data that show increased expression of CYP1A1 upon incubation with viable S. gallolyticus cells.

\section{Induction of CYP1 Expression by S. gallolyticus Is Dependent on AhR}

Polycyclic aromatic hydrocarbon (PAH) substrates, such as $3 \mathrm{MC}$, of CYP1 enzymes interact with the intracellular AhR to induce CYP1 expression. After the subsequent binding of this AhR-PAH complex to several cofactors, it translocates to the nucleus to activate a xenobiotic response element (XRE) that is present in the promoter regions of the CYP1A1, CYP1A2, and CYP1B1 genes (McMillan and Bradfield, 2007) (Figure 3A). To examine whether S. gallolyticus also targets AhR, the induction of CYP1A1, CYP1A2, and CYP1B1 was examined in HT29 cells in combination with $3 \mathrm{MC}$. These experiments showed that $S$. gallolyticus significantly increased CYP1A1, CYP1A2, and $C Y P 1 B 1$ and had an additive effect on $0.001 \mu \mathrm{M} 3 \mathrm{MC}$ mediated CYP1A1 induction (Figure 3B; p $<0.05$ ). S. gallolyticus also had a slight additive effect on $3 \mathrm{MC}$ stimulation for both CYP1A2 and CYP1B1 (Figure 3B), although this was not significant. Furthermore, S. gallolyticus induced CYP1 expression in a concentration-dependent manner, similar to that of CYP1A1 (Figure 3C; $\mathrm{p}<0.001$ ). An AhR antagonist that prevents the binding of PAHs to this receptor (Kim et al., 2006) was added to cocultures to evaluate whether S. gallolyticus also depends on AhR. Preincubation of HT-29 cells with this AhR inhibitor clearly blocked the upregulation of CYP1A1 (Figure 3D), CYP1A2, and CYP1B1 (Supplementary Figure S4) by both $3 \mathrm{MC}$ and S. gallolyticus. Taken together, these results show that CYP1 induction by $S$. gallolyticus is mediated by an AhR-dependent mechanism. 
A

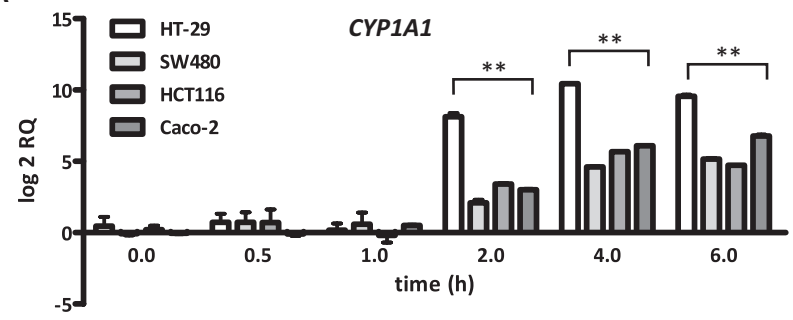

B

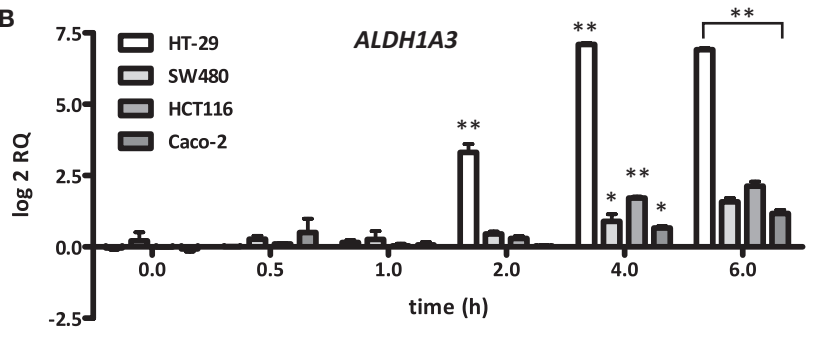

C

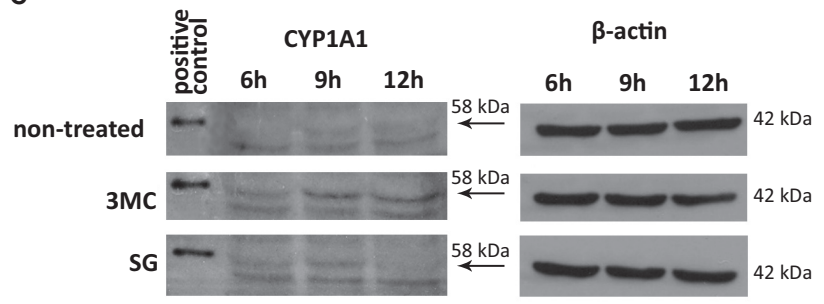

D

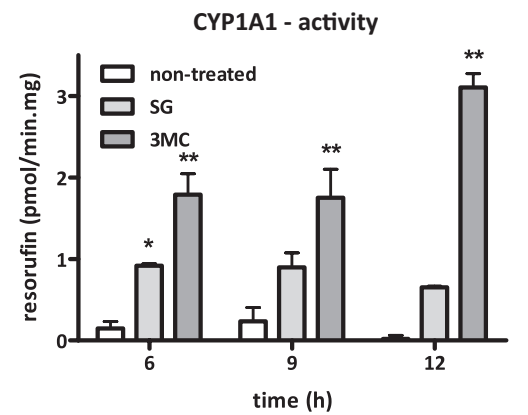

FIGURE 2 | S. gallolyticus-induced CYP1A1 expression. The expression of (A) CYP1A1 and (B) ALDH1A3 was evaluated by GPCR in the CRC cell lines HT-29, SW480, HCT116, and Caco-2 upon 2, 4, and $6 \mathrm{~h}$ of incubation with $\mathrm{S}$. gallolyticus UCN34. Note that the expression of CYP1A1 is highly similar in all investigated cell lines. Two-way ANOVA was performed to determine significant changes ( ${ }^{\star} p<0.05$; ${ }^{* *} p<0.01$ ). (C) Protein expression of CYP1A1 in Caco-2 cells was investigated by Western blotting after exposure to $S$. gallolyticus or $3 \mathrm{MC}$ for 6,9 , and $12 \mathrm{~h}$. The arrows indicate the position of CYP1A1 protein $(58 \mathrm{kDa})$. The replicate blots shown in Supplementary Figure $\mathbf{S} 3$ illustrate that only the indicated band of $58 \mathrm{kDa}$ is detected by several different CYP1A1 antibodies and confirm that only this reactive band specifically appears upon stimulation with $3 \mathrm{MC}$. The right panel shows the corresponding $\beta$-actin protein expression levels (42 kDa). (D) CYP1A1 enzyme activity was measured by the 7-EROD assay. The bars indicate the amounts of picomoles resorufin produced per minute per milligram protein. Two-way ANOVA was performed to determine significant changes $\left({ }^{*} \mathrm{p}<0.05 ;{ }^{* *} \mathrm{p}<0.01\right)$. $R Q$, relative quantity; non-treated cells; 3MC, 3methylcholanthrene; SG, S. gallolyticus.

\section{Increased CYP1 Expression Is Not Specific for S. gallolyticus}

To investigate whether the induction of CYP1A1 is a specific feature of $S$. gallolyticus, the expression of this gene was investigated upon coincubation of HT-29 cells with other S. bovis and other intestinal bacterial strains. Besides S. gallolyticus UCN34, the other S. bovis group strains S. macedonicus CIP105685T, S. infantarius NCTC8133, and S. gallolyticus NTB1 and 1293 increased CYP1A1 gene expression (Supplementary Figure S5A). From the other intestinal bacteria, E. faecalis and E. cloacae were strong inducers of CYP1A1 gene expression in a concentration-dependent manner $(\mathrm{p}<0.01)$ (Supplementary Figure S5B). Intermediate activity was observed for S. lugdunensis, E. coli Nissle 1917, and S. typhimurium. Contrarily, coincubation of HT-29 cells with E. coli NTB5 did not result in an induction of CYP1A1 and might even reduce the expression of this gene (Supplementary Figure S5C). Moreover, the additive effect of S. gallolyticus in combination with $0.001 \mu \mathrm{M}$ 3MC (Figure 3B) was not observed for E. coli NTB5 (Supplementary Figures S5C, D). Thus, these data show that CYP1 induction is not specific for S. gallolyticus and might confer a more general mechanism among a subset of intestinal bacteria.

\section{A S. gallolyticus-Associated Factor Present in the Secretome Induces CYP1A1 Expression}

A remarkable finding was the fact that the intracellular AhR is stimulated by $S$. gallolyticus cells, which lack the ability to invade CRC cells (Boleij et al., 2011). This suggests that these bacteria release a factor themselves, convert and activate a medium component, or provoke the expression of a diffusible host factor that re-enters CRC cells to induce CYP1A1 expression. To confirm this hypothesis, secretome from S. gallolyticus (SGS) was filtered and added to fresh Caco- 2 cells for 4, 8, and $12 \mathrm{~h}$ and to HT29-cells for $12 \mathrm{~h}$. As shown in Figure 4A and Supplementary Figure S5E, SGS induced CYP1A1 expression in Caco-2 cells and HT29-cells ( $\log 2$ RQ 3.0; $\mathrm{p}<0.01)$. Interestingly, secretomes from $E$. faecalis only marginally induced CYP1A1 expression after $12 \mathrm{~h}(\log 2 \mathrm{RQ}$ 1.5 ; NS), whereas viable E. faecalis cells strongly induced expression of this gene (Supplementary Figure S5A). In line with the previous results, secretomes from E. coli NTB5 had no effect on CYP1A1 expression. Secretomes from other $S$. bovis-group bacteria, such as S. gallolyticus subsp. pasteurianus, subsp. macedonicus, and subsp. gallolyticus, S. equinus, or S. lutetiensus, were, however, unable to induce CYP1A1 gene expression (Supplementary Figure S5E). These results confirm the idea that a S. gallolyticus-associated factor present in the secretome of strain UCN34 induces CYP1 gene expression through the AhR; however, why secretomes of other strong inducers of CYP1 are unable to stimulate AhR needs to be resolved.

\section{SGS Increases the DNA-Damaging Effect of $3 \mathrm{MC}$ in CRC Cells}

Next, we tested whether CYP1 upregulation by S. gallolyticus may contribute to the DNA-damaging effect of $3 \mathrm{MC}$. To test this hypothesis, Caco- 2 cells were first incubated in SGS for $6 \mathrm{~h}$ to 


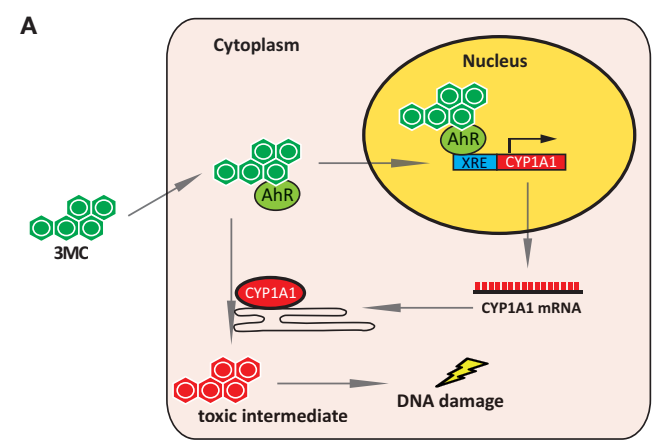

C

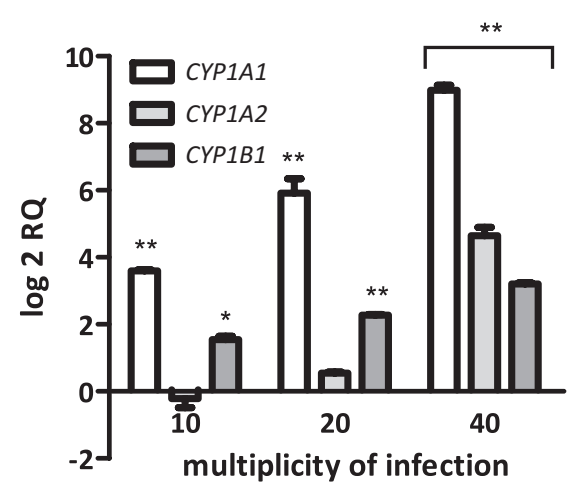

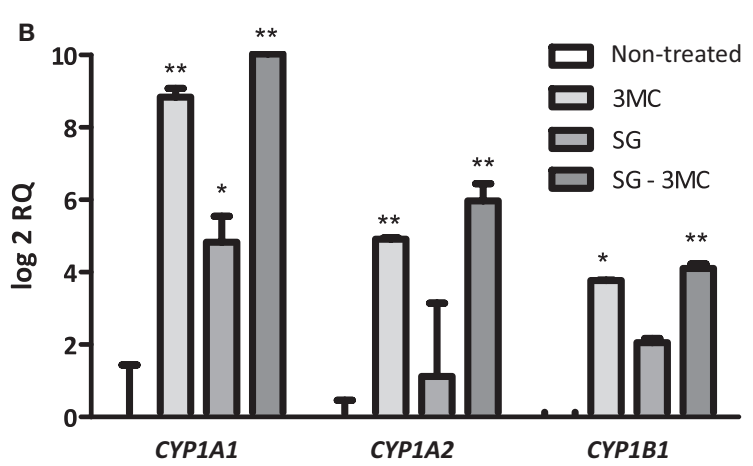

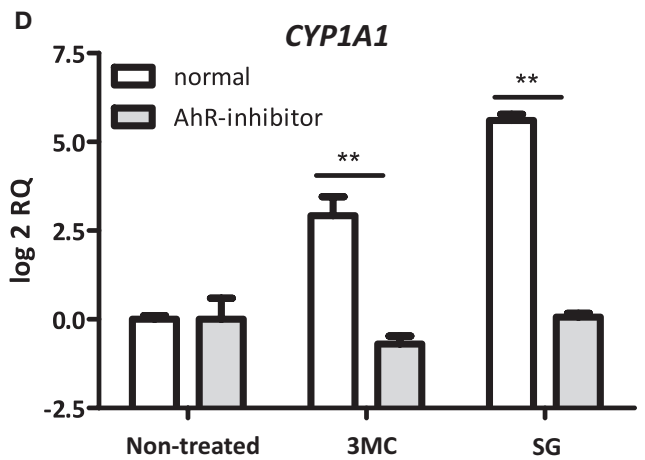

FIGURE 3 | Bacterial Induction of CYP1A1, CYP1A2, and CYP1B1. (A) Model for AhR-dependent gene regulation. Polycyclic aromatic hydrocarbons (PAHs) diffuse into the cell and bind to the intracellular Aryl hydrocarbon receptor (AhR). Next, this complex translocates into the nucleus and binds to an XRE-response element, as present in the CYP1A1 promoter region. After transcription/translation, CYP1A1 acts in the endoplasmatic reticulum as a phase I enzyme that converts PAHs to more toxic intermediates that can form DNA adducts. (B) CYP1A1, CYP1A2, and CYP1B1 induction was investigated in the presence or absence of the AhR ligand 3MC. Note that S. gallolyticus UCN34 (SG) and 3MC have an additive effect on CYP1A1, CYP1A2, and CYP1B1 induction. (C) The expression of CYP1A1, CYP1A2, and CYP1B1 upon incubation with S. gallolyticus UCN34 at increasing multiplicity of infection was compared to non-treated control cells. (D) The induction of CYP1A1 by $3 \mathrm{MC}$ or S. gallolyticus UCN34 in HT-29 cells, in the presence or absence of an AhR-inhibitor, was investigated by qPCR. Statistical analysis by two-way ANOVA was performed to determine significant changes $\left({ }^{\star} \mathrm{p}<0.05\right.$; ${ }^{\star \star} \mathrm{p} p<0.01$ ).

prime CYP1 expression, after which the level of 3MC-induced DNA damage was compared to that in untreated cells by the COMET assay, which quantifies the level of DNA damage on the cellular level. As shown in Figures 4B-D, the DNA damaging effect of $0.1 \mu \mathrm{M} 3 \mathrm{MC}$ was significantly increased by preincubation of Caco- 2 cells in SGS $(p<0.05)$. In contrast, priming of these cells with secretomes from E. faecalis or E. coli did not increase $3 \mathrm{MC}$ genotoxicity. In fact, secretome from E. faecalis had even a surprising inhibitory effect on 3MCinduced DNA damage $(\mathrm{p}<0.05)$. It is presently unknown how this relates to the induction of CYP1 expression by viable $E$. faecalis cells. Together, these results show that secreted or otherwise released S. gallolyticus-associated factors can prime CRC cells towards an increased susceptibility to 3MC-induced DNA damage under the applied experimental conditions.

\section{No Clear Link Between COX-2 Expression, PGE2 Release, Cell Proliferation, and AhR Activation}

It was previously shown that the related bacterium $S$. infantarius NCTC 8133, now reclassified as S. equinus, induced COX-2 expression in colon epithelial cells in vitro (Ellmerich et al., 2000). Moreover, it has been described that COX2 expression can, similarly to CYP1A1, also be activated via AhR-ligand binding to the XRE promotor (Degner et al., 2007). Therefore increased AhR activity and CYP1A1 might also relate to COX-2 upregulation. S. gallolyticus UCN34 showed a low, but significant, induction of COX-2 expression to a $\log 2 \mathrm{RQ}$ of 1.6 in HT-29 cells after 2 and $4 \mathrm{~h}(\mathrm{p}=0.017)$ of coculturing (Figure 5A). However, at protein level, PGE2 release was not significantly increased in HT29 cells compared to control cells after $24 \mathrm{~h}$ exposure to SGS (74.2 vs. $45.0 \mathrm{pg} / \mathrm{ml}, \mathrm{p}>0.05$, Figure 5B). Furthermore, it has been described that AhR activation may lead to cell proliferation. Previously, it was shown that $S$. gallolyticus increases cell proliferation of several colon epithelial cell lines, dependent on the bacterial strain (Kumar et al., 2018). We show here that at least SGS of strain UCN34 and NTB12 are unable to increase cell proliferation in HT29, SW480, HCT116, and Caco-2 cells. NTB12 even decreased cell proliferation significantly in HCT116 cells (Figure 5C). Similarly, S. lutetiensis NTB2 consistently decreased cell proliferation in Caco-2, SW480, and HCT116 cells. 
A

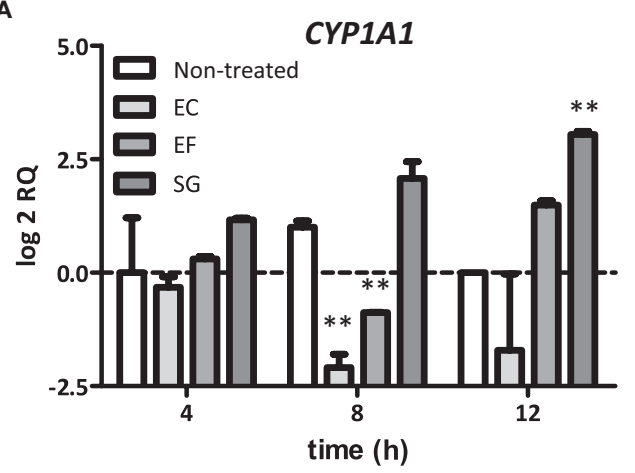

B

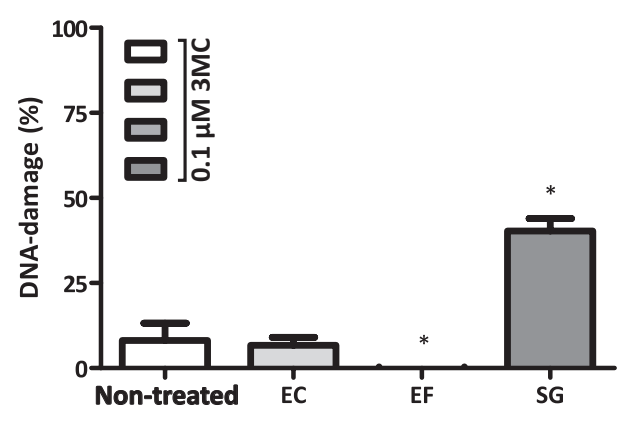

D

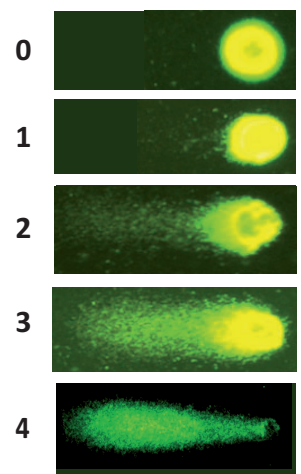

FIGURE 4 | SGS induced CYP1A1 expression and increase in the DNA-damaging effect of 3MC. (A) Expression of CYP1A1 in Caco-2 cells was examined by qPCR after exposure of these cells to the secretomes of E. coli NTB 5 (EC), S. gallolyticus UCN34 (SG), and E. faecalis 19433 (EF). Note that only exposure to secretomes from S. gallolyticus UCN34 resulted in increased CYP1A1 levels after 8 and $12 \mathrm{~h}\left({ }^{\star *} \mathrm{p}<0.01\right)$. (B) DNA damage under the conditions described in Panel (A) were measured by the COMET assay ( $\left.{ }^{*} \mathrm{p}<0.05\right)$. To induce low levels of DNA damage, incubation was prolonged for $18 \mathrm{~h}$ after addition of $0.1 \mu \mathrm{M} 3 \mathrm{MC}$ to the culture medium. Reference ranges were determined by the incubation of Caco-2 cells without $3 \mathrm{MC}\left(0 \%\right.$ damage) and with $100 \mu \mathrm{M} \mathrm{H} \mathrm{O}_{2}(100 \%$ damage). Only exposure to SGS from S. gallolyticus UCN34 in combination with 3MC yielded increased levels of DNA damage compared to $3 \mathrm{MC}$ alone (non-treated). ( ${ }^{\star} \mathrm{P}<0.05$ ) (C) The increase in DNA damage by SGS in combination with 3MC is mainly due to an increased number of cells with DNA damage and with high levels of DNA damage (COMET scores 3 and 4). Two-way-ANOVA $(p<0.01)$. (D) Representative fluorescence microscope images with assigned COMET scores used for the quantification of DNA damage as shown in $(\mathbf{B}, \mathbf{C})$.

Only S. gallolyticus subsp. pasteurianus NTB7 and 992 were significantly increasing growth of HCT116 cells ( $p<0.001)$. Hence, a clear correlation between secretomes, AhR-activation, cell proliferation, and PGE2 release is not observed from these results.

\section{S. gallolyticus Increases CYP1A1 Expression In Vivo}

To verify that CYP1A1 activation via $\mathrm{AhR}$ in in vitro cell models is also observed in vivo, wild-type C57bl6 mice were colonized with S. gallolyticus UCN34 after 5 days of antibiotic treatment with kanamycin/doxycyclin. Mice were either pretreated with vehicle or with daily gavage of $10 \mathrm{mg} / \mathrm{kg} \mathrm{AhR}$ inhibitor $\mathrm{CH} 223191$. After 1 week of colonization, a clear induction of CYP1A1 mRNA was detected in the cecum of mice colonized with S. gallolyticus, which was significantly reduced in mice fed AhR inhibitor (Figure 6A). Mice colonization was measured in fecal pellets with levels of $1-3^{\star} 10^{9} \mathrm{CFU} / \mathrm{g}$ stool at 3 days postcolonization waning to levels of $1-10 \times 10^{7} \mathrm{CFU} / \mathrm{g}$ stool at 1 week (Figure 6B and Supplementary Figure S6). As levels of S. gallolyticus started to drop at 1 week, we tested how long colonization would persist and whether effective immune response would eliminate $S$. gallolyticus. We observed colonization up to 21-30 days after which S. gallolyticus in stool was below the detection level. Simultaneous with reduced colonization levels, IgGs detecting immobilized S. galloltyicus in an ELISA assay were present in serum of mice colonized with S. galloltyicus (Figure 6C). To confirm that a B-cell response was initiated, IL4 mRNA was measured and detected at 1 week with increasing levels 4 weeks postcolonization (Figure 6D). CYP1A1 was no longer increased at 4 weeks postinoculation when colonization of S. gallolyticus disappears. In addition, in vivo, we did not observe any increase in prostaglandin expression at mRNA and protein level (data not shown) or differences in cell proliferation in proximal or distal colon (Figure 6E and Supplementary Figure S7). The cecum showed some immune cell infiltration and reactive epithelial changes with S. gallolyticus colonization (Supplementary Figure S8), but this was not significantly different from sham mice, and no differences were observed between mice treated with vehicle or AhR inhibitor. No inflammation or aberrant growth was observed in the cecum or colon. Together, these data show that also in vivo CYP1 is 
A

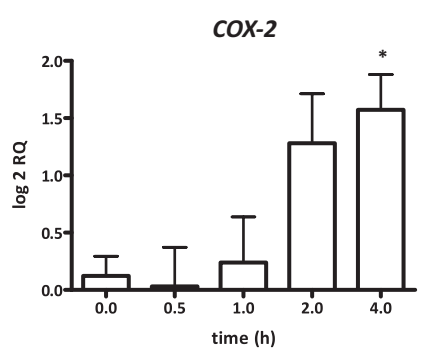

C

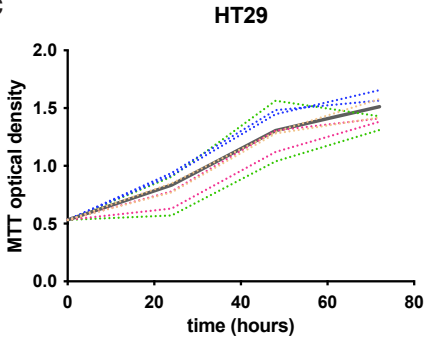

sW480

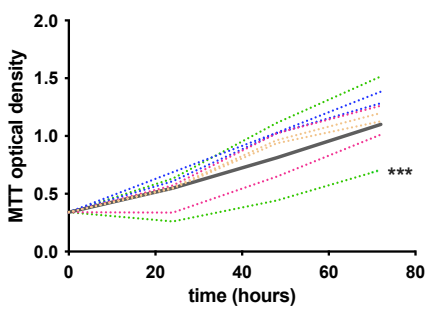

$\begin{array}{lll}\text { — control } & \ldots . . . & \text { lutetiensis-equinus NTB2 } \\ & \ldots . . & \text { lutetiensis-equinus NCTC8133 } \\ \ldots . . . & \text { gallolyticus UCN34 } \\ \ldots . . . & \text { gallolyticus NTB12 }\end{array}$
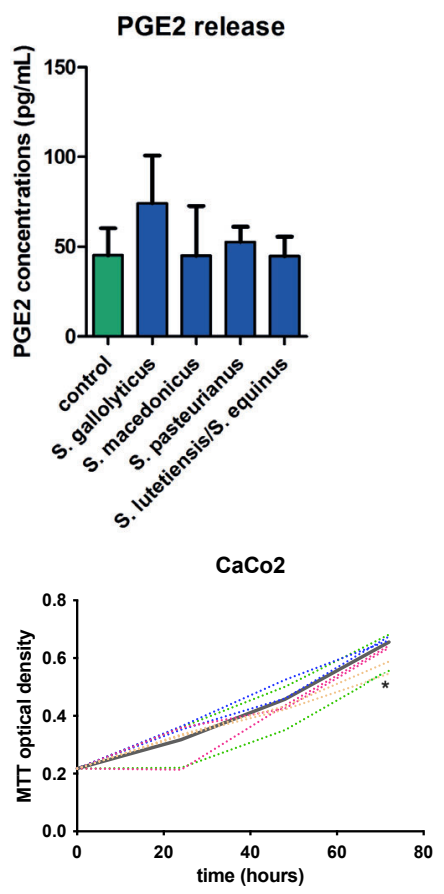

HCT116

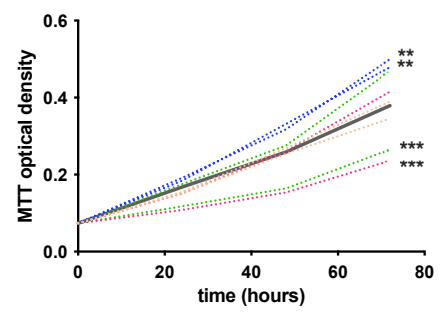

..... pasteurianus NTB7

pasteurianus 992

macedonicus 19AS

macedonicus ACA-DC205

FIGURE 5 | COX-2 induction, PGE2 release, and cell proliferation by SGS. (A) Expression of COX-2 in HT29 cells was examined by qPCR after exposure of these cells to S. gallolyticus UCN34 at an MOI of 20 for $4 \mathrm{~h} \mathrm{COX-2}$ was significantly upregulated as determined by one-way ANOVA (*p < 0.05). (B) PGE2 release after exposure to secretomes of S. gallolyticus subsp. gallolyticus (UCN34/NTB12), S. gallolyticus subsp. pasteurianus (NTB7/992), S. gallolyticus subsp. macedonicus (19AS/ACA-DC-205), and S. equinus/lutetiensis (NCTC8133/NTB2). No significant increase in PGE2 release was observed after 24 h. (C) Cell growth was measured with MTT assay at 24, 48, and $72 \mathrm{~h}$ in HT29, Caco-2, HCT116, and SW480 cells. Each secretome condition was performed in quadruplicate. The area under the curve was calculated for each condition and compared to control cells using independent t-test. HCT116 cells were most sensitive to S. bovis group bacteria. In none of the conditions, S. gallolyticus subsp. gallolyticus secretomes induced cell growth. S. gallolyticus subsp. gallolyticus NTB12 even inhibited cell growth in HCT116 cells. Only S. gallolyticus subsp. pastereurianus strains 992 and NTB7 were able to induce cell growth in HCT116 cells. S. lutetiensis NTB2 consistently inhibited cell growth in CaCo-2, SW480, and HCT116 cells. ${ }^{*} \mathrm{p}<0.05,{ }^{* *} \mathrm{p}<0.01,{ }^{\star \star *} \mathrm{p}<0.001$.

induced by S. gallolyticus and that S. gallolyticus is effectively recognized and eliminated by the mouse intestinal immune system.

\section{DISCUSSION}

Accumulating evidence supports a relationship between intestinal bacteria and the pathogenesis of CRC (Wang et al., 2008; Wu et al.,
2009; Cuevas-Ramos et al., 2010; Rubinstein et al., 2019; Dziubanska-Kusibab et al., 2020; Pleguezuelos-Manzano et al., 2020). For S. gallolyticus, the clinical relation with CRC is unambiguous. Detection of S. gallolyticus in blood is an indication for colonoscopy (Boleij et al., 2011); there is an increased colonization reported in CRC patients (Jans and Boleij, 2018), and in large seroepidemiological studies, a significant exposure to S. gallolyticus antigens in serum was found in CRC patients (Boleij et al., 2012; Butt et al., 2016; Butt et al., 2017; Butt et al., 2019). However, it is still debated whether S. gallolyticus 
A
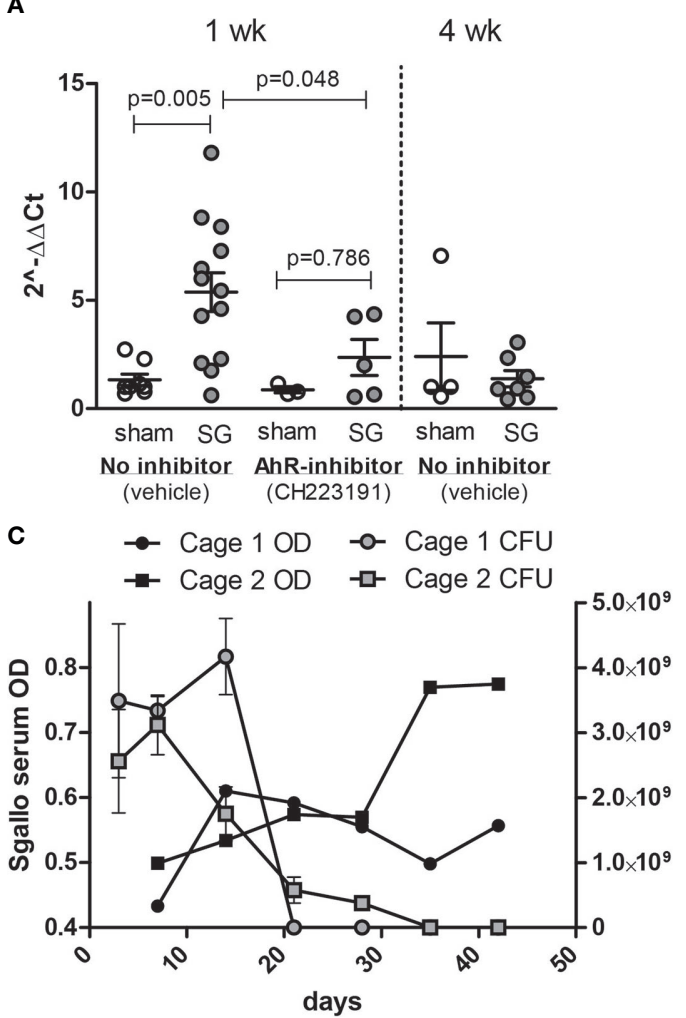

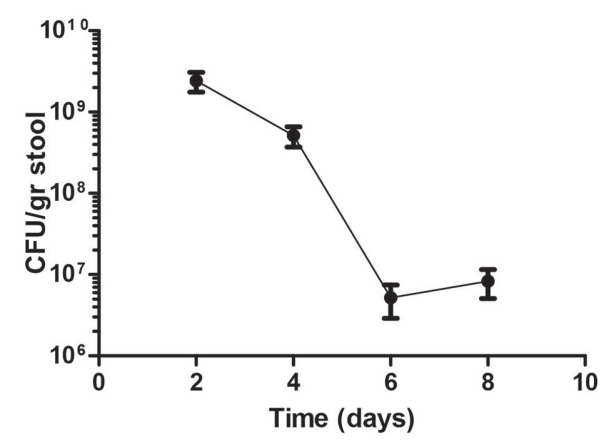

D

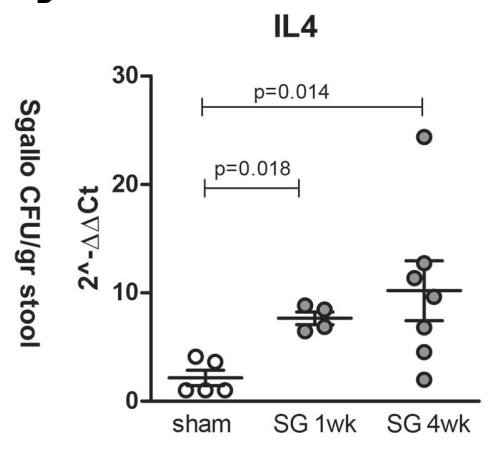

E

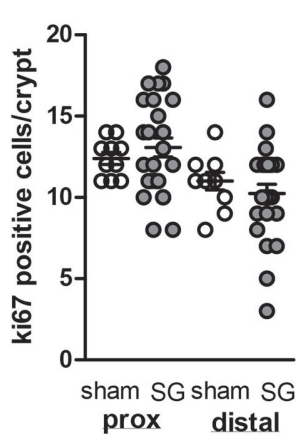

FIGURE 6 | Colonization of C57bl6 mice leads to CYP1A1 induction in cecum and effective clearance of $S$. gallolyticus. (A) Compared to sham mice $(n=8)$, S. galloltyicus UCN34 colonized mice show significantly increased levels of CYP1A1 at 1 week postcolonization $(n=13$, Mann-Whitney U-test $p=0.005)$ that is not observed in mice treated with daily gavage of the AhR-inhibitor CH223191 $(n=5)$. At 4 weeks postcolonization, CYP1A1 induction is back to normal levels $(n=7)$. (B) Stool colonization of UCN34 monitored at $2(n=4), 4(n=8), 6(n=9)$, and 8 days $(n=14)$ postcolonization. Two out of five AhR-treated animals lost colonization by day 8 , whereas 3 out of 13 vehicle-treated-mice lost colonization. The colonization levels at days 6-8 were not significantly different for vehicle or AhR-treated animals (Mann-Whitney U-test, $p=0.12$, Supplementary Figure S6). (C) Colonization of S. galloltyicus UCN34 over time up to 42 days (6 weeks) with weekly serum collections (without vehicle or AhR-inhibitor) $(n=8)$. CFU of S. galloltyicus in gray circles (cage $1 ; n=4)$ and squares (cage 2;n = 4) decreased after 3 weeks significantly, while antibody production starts to increase at 2-3 weeks postcolonization (black circles and squares). Cages were visualized separately because of differences in colonization and antibody responses between the two cages. The treatment, inoculation, and handling of the animals in these two cages was similar. (D) IL4 mRNA production is increased at 1 and 4 weeks post-UCN34 colonization compared to sham mice (Mann-Whitney U-test $p=0.018$ and 0.014 , respectively). (E) ki67 stained slides were scored for total number of positive ki67 cells per crypt; for each mice, five crypts were counted and plotted. No difference in ki67-positive cells was seen in proximal and distal colon at 1 week postcolonization compared to sham.

merelyprofits from the tumor microenvironment and/or whether S. gallolyticus can also contribute to CRC development. The aim of this study was to find S. gallolyticus-induced pathways in CRC cells. By a microarray profiling approach of in vitro-cultured CRC cells, we discovered that S. gallolyticus is a potent inducer of cellular biotransformation enzymes CYP1 and ALDH1. In particular, our data show that S. gallolyticus induces CYP1 enzyme production through AhR by a component or components present in the secretome (SGS) that remains to be identified. Clearly, SGS increases the DNA damaging effect of $3 \mathrm{MC}$ in CRC cells, showing that $S$. gallolyticus is somehow able to functionally alter the biotransformation capacity of Caco-2 cells in vitro and also induces the same pathway through AhR in vivo in wild-type C57bl6 mice.

The expression of CYP1 is induced by their toxic substrates, mainly polycyclic aromatic hydrocarbons (PAHs) present in charbroiled food, environmental pollutants accumulating in the food chain, such as digoxin, and cigarette smoke. These toxic substrates bind to AhR that translocates to the nucleus and activates transcription of genes with an AhR response element such as CYP1 and ALDH (Dietrich and Kaina, 2010). Depending on the substrate, induction of biotransformation enzymes contributes to either the detoxification or bioactivation of these toxins and thereby modulate the carcinogenic potential of these compounds (Shimada et al., 1992; Kim et al., 2009). CYP1 enzymes oxidize or hydrolyze (toxic) compounds (phase I metabolism) often resulting into more reactive intermediates (Eastman and Bresnick, 1979), a process that is also called bioactivation. This is often followed by conjugation reactions catalyzed by phase II enzymes, such as glutathione S-transferases (GSTs) or UDP-glucuronosyltransferases (UGTs) to deactivate these compounds and make them more water soluble for 
clearance from the body. Biotransformation of PAHs by CYP1 often results in chemical intermediates that are more genotoxic than their precursors. These intermediate carcinogens can covalently bind to chromosomal DNA that interferes with correct DNA replication and in turn may result in increased mutation rates (Eastman and Bresnick, 1979; Spink et al., 2002). Induction of CYP1 enzymes is mediated through the AhR that can interact with a wide range of structurally diverse ligands (Denison and Nagy, 2003; Abel and Haarmann-Stemmann, 2010). Here, we show that a multitude of intestinal bacteria can induce CYP1, as exemplified by $S$. gallolyticus. CYP1 is inhibited in vitro and in vivo when blocking the AhR with $\mathrm{CH} 223191$. Induction of phase I enzymes may result in the accumulation of toxic intermediates, which is corroborated by the observation that priming CRC cells with secretomes of S. gallolyticus results in the increased formation of DNA damage upon exposure of these CRC cells to 3MC. 3MC is converted into more carcinogenic intermediates such as dihydrodiol- or 2-hydroxy-3MC that has higher DNA-binding efficiencies than the parent compound $3 \mathrm{MC}$. These bioactivation events thereby result in increased DNA adduct formation and consequently higher mutation rates (Eastman and Bresnick, 1979). However, from these results, we cannot firmly conclude that the potentiation of $3 \mathrm{MC}$ by secretomes of S. gallolyticus depends on AhR activation. Other S. gallolyticus-associated factors, which act in an AhR-independent manner, may also add to the observed increase in DNA damage. Nonetheless, our current in vitro experiments show the potency of a multitude of bacteria to modulate CYP1 within CRC cells.

In vivo, the activation of the $\mathrm{AhR}$ contributes to the regulation of cell growth via a negative feedback mechanism mediated by the AhR repressor (AhRR) (Hahn et al., 2009). It was previously shown that AhRR expression levels are modestly decreased in precancerous colonic polyps and more profoundly decreased in primary invasive colon carcinomas (Zudaire et al., 2008). This underscores the importance of $\mathrm{AhR}$ stimulation during malignant transformation. Besides this, it has been shown that CYP1 enzymes are poorly expressed in healthy colonic epithelium but overexpressed in colonic adenomas and carcinomas (McKay et al., 1993; Mercurio et al., 1995; Ding and Kaminsky, 2003). Our current data show that bacteria have the potency to interfere with AhR-mediated induction of CYP1A1 in vitro and in vivo and thereby could modulate important cellular processes, such as carcinogenesis of foodderived PAHs.

Our in vivo data show that colonization with S. gallolyticus is only present 3 weeks postinoculation and exerts an effective antibody response in the serum of the mice. In line with this observation, S. gallolyticus disappears from the colon, and CYP1 induction in the ceca of the mice drops back to normal levels. This suggest that active colonization is required for the in vivo observed induction of biotransformation ability by CYP1. Whether this induction in vivo also contributes to increases in DNA damage by PAHs has not been investigated yet. Alternatively, AhR activation in intestinal epithelial cells has also been linked to intestinal barrier function and an effective immune response (Yu et al., 2018). Hence, the activation of AhR by (opportunistic) pathogens in vivo might have a dual role and also play a role in effective protection against pathogens. Alternatively, AhR deficiency in vivo has been linked to chemical-induced tumorigenesis in infection models with DSS and Citrobacter rodentium (Diaz-Diaz et al., 2016; Metidji et al., 2018). In the latter model, AhR was shown to negatively regulate the Wnt- $\beta$-catenin pathway and prevent the development of tumors by AOM. While $S$. gallolyticus secretomes may potentiate $3 \mathrm{MC}$ in vitro in epithelial cells without affecting cell proliferation, the outcome in vivo might depend on the level of AhR stimulation and cell proliferation by $S$. gallolyticus and should be further investigated.

Unfortunately, until now we were unable to identify the molecular structure of the S. gallolyticus-associated factor(s) that mediate increased CYP1 expression in CRC cells. Candidates are shed structural components of the bacterial surface or excreted metabolites. Alternatively, this factor may be formed by S. gallolyticus from a precursor that is present in the growth medium. As killed S. gallolyticus did not induce CYP1 expression, we consider the latter two options as most likely. A possible mechanism could be the bacterial conversion of tryptophan into indoles (Nebert and Karp, 2008), or the production of short-chain fatty acids (Jin et al., 2017), which are known ligands of AhR. Alternatively, S. gallolyticus may induce the production or release of a factor from CRC cells, which can (re)enter CRC cells. Clearly, future biochemical studies are required to identify the $S$. gallolyticus-associated or more broadly intestinal bacteria-associated factors, which can induce CYP expression in an AhR-dependent manner.

It should be realized that a potential caveat of our study is that only transformed CRC cell lines were used, in which signaling pathways are already different from normal epithelial cells. Unfortunately, our attempts to confirm our data in primary healthy colonic cells were unsuccessful due to difficulties in maintaining their viability during the experimental conditions of this study. However, S. gallolyticus could effectively induce CYP1 expression in healthy C57bl6mice, which indicates that AhR activation is not a sole feature of CRC cells.

The increased colonization of $S$. gallolyticus observed with $\mathrm{CRC}$ was recently confirmed in $\mathrm{APC}{ }^{\text {min }}$ and APC/notch mice, where a clear increase in colonization was reported, but no increase in tumor burden with S. galloltyicus subp. gallolyticus UCN34 was observed (Aymeric et al., 2018). However, Kumar et al. showed that tumor burden and cell proliferation depended on the S. gallolyticus strain used in vitro and in vivo, which was observed for strain TX20005 but not TX20008 (Kumar et al., 2018). Our data support these findings; S. gallolyticus UCN34 was effectively cleared from wild-type C57bl6 mice and did not increase cell proliferation in vitro and in vivo. Furthermore, our unpublished pilot in APC $^{\text {min }}$ mice at 6 weeks shows no increase in tumor burden in these susceptible mice upon $S$. gallolyticus UCN34 colonization. These strain level effects on cell proliferation for a multitude of CRC-associated bacteria were recently also shown by us for Fusobacterium nucleatum and Clostridium species (Taddese et al., 2020). These combined data 
suggest effective long-term colonization with S. gallolyticus only when tumors are present and, more importantly, that strain level differences are important for the observed effects.

In conclusion, our data provide intriguing evidence for the bacterial potential, especially S. gallolyticus subsp. gallolyticus, to interrelate with AhR-mediated pathways for cellular biotransformation (CYP1) that could potentially contribute to DNA damage and/or is involved in effective intestinal clearance of (opportunistic) pathogens protecting the epithelial barrier. To confirm the AhR-mediated effects in vitro, AhR reporter cell lines could aid in understanding which bacteria or which component in the secretome exert the induction of CYP1 genes. Furthermore, in vivo, the role of S. gallolyticus or related bacteria on epithelial and immune compartment could be further explored by the use of AhR knockout-mice crossed with villin-cre or bone-marrow chimera models with AhR knockout and wild-type mice to deduct the role of epithelial and immune cells in the S. gallolyticus AhR interactions. When the component in the secretome is known, also titration studies could shed light on the impact of such compound in vivo. Our data underscore the need for a better understanding of hostmicrobe interactions during $\mathrm{CRC}$, since it builds on accumulating studies that implicate bacteria in the initiation and progression of CRC. Emerging studies moving from association to causation in microbiome research will in the near future further shed light on species and even straindependent actions of microbiota on CRC development that, in our opinion, are increasingly necessary due to species- and strain-dependent effects; e.g., not all Streptococci are equal.

\section{DATA AVAILABILITY STATEMENT}

The datasets presented in this study can be found in online repositories. The names of the repository/repositories and accession number(s) can be found below: https://www.ncbi. nlm.nih.gov/geo/, GSE29295.

\section{REFERENCES}

Abdulamir, A. S., Hafidh, R. R., and Abu Bakar, F. (2010). Molecular Detection, Quantification, and Isolation of Streptococcus Gallolyticus Bacteria Colonizing Colorectal Tumors: Inflammation-Driven Potential of Carcinogenesis via IL-1, COX-2, and IL-8. Mol. Cancer 9 (1), 249. doi: 10.1186/1476-4598-9-249

Abel, J., and Haarmann-Stemmann, T. (2010). An Introduction to the Molecular Basics of Aryl Hydrocarbon Receptor Biology. Biol. Chem. 391 (11), 12351248. doi: 10.1515/bc.2010.128

Aboutabl, M. E., Zordoky, B. N., and El-Kadi, A. O. (2009). 3-Methylcholanthrene and Benzo(a)Pyrene Modulate Cardiac Cytochrome P450 Gene Expression and Arachidonic Acid Metabolism in Male Sprague Dawley Rats. Br. J. Pharmacol. 158 (7), 1808-1819. doi: 10.1111/j.1476-5381.2009.00461.x

Aksoy, N., and Akinci, O. F. (2004). Mucin Macromolecules in Normal, Adenomatous, and Carcinomatous Colon: Evidence for the Neotransformation. Macromol. Biosci. 4 (5), 483-496. doi: 10.1002/ mabi.200300099

Andres-Franch, M., Galiana, A., Sanchez-Hellin, V., Ochoa, E., Hernandez-Illan, E., Lopez-Garcia, P., et al. (2017). Streptococcus Gallolyticus Infection in

\section{ETHICS STATEMENT}

The animal study was reviewed and approved by the Johns Hopkins University Animal Care and Use Committee.

\section{AUTHOR CONTRIBUTIONS}

$\mathrm{AB}, \mathrm{RT}, \mathrm{RR}$, and $\mathrm{DD}$ performed and conceptualized in vitro experiments. AB, XW, and SW performed and conceptualized mice experiments. AB, HT, and DS conceptualized the study and were responsible for study design and preparation/revision of the manuscript. All authors contributed to the article and approved the submitted version.

\section{FUNDING}

$\mathrm{AB}$ was supported by the Dutch Cancer Society (KWF; project KUN 2006-3591), NWO Rubicon grant 825.11.031, and Veni grant 016.166 .089 ; RR was supported by the Dutch Digestive Diseases Foundation (MLDS; project WO 10-53); and RT was supported by the RIMLS grant 014-058.

\section{ACKNOWLEDGMENTS}

We like to thank Hennie Roelofs, Wilbert H.M. Peters, Guus Kortman, Cynthia Sears, and Tanja Schülin for the interesting and helpful discussions on the topic. We thank Joris Veltman and Christian Gilissen for technical assistance regarding microarray performance and data analysis.

\section{SUPPLEMENTARY MATERIAL}

The Supplementary Material for this article can be found online at: https://www.frontiersin.org/articles/10.3389/fcimb.2021. 740704/full\#supplementary-material

Colorectal Cancer and Association With Biological and Clinical Factors. PloS One 12 (3), e0174305. doi: 10.1371/journal.pone.0174305

Anwar-Mohamed, A., and El-Kadi, A. O. (2009). Sulforaphane Induces CYP1A1 mRNA, Protein, and Catalytic Activity Levels via an AhR-Dependent Pathway in Murine Hepatoma Hepa 1c1c7 and Human HepG2 Cells. Cancer Lett. 275 (1), 93-101. doi: 10.1016/j.canlet.2008.10.003

Aymeric, L., Donnadieu, F., Mulet, C., du Merle, L., Nigro, G., Saffarian, A., et al. (2018). Colorectal Cancer Specific Conditions Promote Streptococcus Gallolyticus Gut Colonization. Proc. Natl. Acad. Sci. U. S. A. 115 (2), E283EE91. doi: 10.1073/pnas.1715112115

Biarc, J., Nguyen, I. S., Pini, A., Gosse, F., Richert, S., Thierse, D., et al. (2004). Carcinogenic Properties of Proteins With Pro-Inflammatory Activity From Streptococcus Infantarius (Formerly S.bovis). Carcinogenesis 25 (8), 14771484. doi: 10.1093/carcin/bgh091

Boleij, A., Dutilh, B. E., Kortman, G. A., Roelofs, R., Laarakkers, C. M., Engelke, U. F., et al. (2012). Bacterial Responses to a Simulated Colon Tumor Microenvironment. Mol. Cell Proteomics 11 (10), 851-862. doi: 10.1074/ mcp.M112.019315

Boleij, A., Muytjens, C. M., Bukhari, S. I., Cayet, N., Glaser, P., Hermans, P. W., et al. (2011). Novel Clues on the Specific Association of Streptococcus 
Gallolyticus Subsp Gallolyticus With Colorectal Cancer. J. Infect. Dis. 203 (8), 1101-1109. doi: 10.1093/infdis/jiq169

Boleij, A., Roelofs, R., Danne, C., Bellais, S., Dramsi, S., Kato, I., et al. (2012). Selective Antibody Response to Streptococcus Gallolyticus Pilus Proteins in Colorectal Cancer Patients. Cancer Prev. Res. (Phila) 5 (2), 260-265. doi: 10.1158/1940-6207.CAPR-11-0321

Boleij, A., van Gelder, M. M., Swinkels, D. W., and Tjalsma, H. (2011). Clinical Importance of Streptococcus Gallolyticus Infection Among Colorectal Cancer Patients: Systematic Review and Meta-Analysis. Clin. Infect. Dis. 53 (9), 870878. doi: $10.1093 / \mathrm{cid} / \mathrm{cir} 609$

Boltin, D., Goldberg, E., Bugaevsky, O., Kelner, E., Birkenfeld, S., Gingold-Belfer, R., et al. (2015). Colonic Carriage of Streptococcus Bovis and Colorectal Neoplasia: A Prospective 17-Year Longitudinal Case-Control Study. Eur. J. Gastroenterol. Hepatol. 27 (12), 1449-1453. doi: 10.1097/MEG. 0000000000000466

Butt, J., Fernández de Larrea, N., Tjalsma, H., Roelofs, R., Kato, I., Martín, V., et al. (2019). Antibody Responses to Flagellin C and Streptococcus Gallolyticus Pilus Proteins in Colorectal Cancer. Sci. Rep. 9 (1), 10847. doi: 10.1038/s41598-01947347-6

Butt, J., Romero-Hernández, B., Pérez-Gómez, B., Willhauck-Fleckenstein, M., Holzinger, D., Martin, V., et al. (2016). Association of Streptococcus Gallolyticus Subspecies Gallolyticus With Colorectal Cancer: Serological Evidence. Int. J. Cancer 138 (7), 1670-1679. doi: 10.1002/ijc.29914

Butt, J., Werner, S., Willhauck-Fleckenstein, M., Michel, A., Waterboer, T., Zörnig, I., et al. (2017). Serology of Streptococcus Gallolyticus Subspecies Gallolyticus and Its Association With Colorectal Cancer and Precursors. Int. J. Cancer 141 (5), 897-904. doi: 10.1002/ijc.30765

Chichlowski, M., and Hale, L. P. (2008). Bacterial-Mucosal Interactions in Inflammatory Bowel Disease: An Alliance Gone Bad. Am. J. Physiol. Gastrointest. Liver Physiol. 295 (6), G1139-G1149. doi: 10.1152/ ajpgi.90516.2008

Collins, A. R. (2004). The Comet Assay for DNA Damage and Repair: Principles, Applications, and Limitations. Mol. Biotechnol. 26 (3), 249-261. doi: 10.1385/ MB:26:3:249

Corredoira, J. C., Alonso, M. P., Garcia, J. F., Casariego, E., Coira, A., Rodriguez, A., et al. (2005). Clinical Characteristics and Significance of Streptococcus Salivarius Bacteremia and Streptococcus Bovis Bacteremia: A Prospective 16Year Study. Eur. J. Clin. Microbiol. Infect. Dis. 24 (4), 250-255. doi: 10.1007/ s10096-005-1314-x

Cuevas-Ramos, G., Petit, C. R., Marcq, I., Boury, M., Oswald, E., and Nougayrede, J. P. (2010). Escherichia Coli Induces DNA Damage In Vivo and Triggers Genomic Instability in Mammalian Cells. Proc. Natl. Acad. Sci. U. S. A. 107 (25), 11537-11542. doi: 10.1073/pnas.1001261107

Degner, S. C., Kemp, M. Q., Hockings, J. K., and Romagnolo, D. F. (2007). Cyclooxygenase-2 Promoter Activation by the Aromatic Hydrocarbon Receptor in Breast Cancer Mcf-7 Cells: Repressive Effects of Conjugated Linoleic Acid. Nutr. Cancer 59 (2), 248-257. doi: 10.1080/01635580701485585

Denison, M. S., and Nagy, S. R. (2003). Activation of the Aryl Hydrocarbon Receptor by Structurally Diverse Exogenous and Endogenous Chemicals. Annu. Rev. Pharmacol. Toxicol. 43, 309-334. doi: 10.1146/annurev. pharmtox.43.100901.135828

Diaz-Diaz, C. J., Ronnekleiv-Kelly, S. M., Nukaya, M., Geiger, P. G., Balbo, S., Dator, R., et al. (2016). The Aryl Hydrocarbon Receptor is a Repressor of Inflammation-Associated Colorectal Tumorigenesis in Mouse. Ann. Surg. 264 (3), 429-436. doi: 10.1097/SLA.0000000000001874

Dietrich, C., and Kaina, B. (2010). The Aryl Hydrocarbon Receptor (AhR) in the Regulation of Cell-Cell Contact and Tumor Growth. Carcinogenesis 31 (8), 1319-1328. doi: 10.1093/carcin/bgq028

Ding, X., and Kaminsky, L. S. (2003). Human Extrahepatic Cytochromes P450: Function in Xenobiotic Metabolism and Tissue-Selective Chemical Toxicity in the Respiratory and Gastrointestinal Tracts. Annu. Rev. Pharmacol. Toxicol. 43, 149-173. doi: 10.1146/annurev.pharmtox.43.100901.140251

Dziubanska-Kusibab, P. J., Berger, H., Battistini, F., Bouwman, B. A. M., Iftekhar, A., Katainen, R., et al. (2020). Colibactin DNA-Damage Signature Indicates Mutational Impact in Colorectal Cancer. Nat. Med. 26 (7), 1063-1069. doi: 10.1038/s41591-020-0908-2

Eastman, A., and Bresnick, E. (1979). Metabolism and DNA Binding of 3Methylcholanthrene. Cancer Res. 39 (11), 4316-4321.
Ellmerich, S., Djouder, N., Scholler, M., and Klein, J. P. (2000). Production of Cytokines by Monocytes, Epithelial and Endothelial Cells Activated by Streptococcus Bovis. Cytokine 12 (1), 26-31. doi: 10.1006/cyto.1999.0521

Ellmerich, S., Scholler, M., Duranton, B., Gosse, F., Galluser, M., Klein, J. P., et al. (2000). Promotion of Intestinal Carcinogenesis by Streptococcus Bovis. Carcinogenesis 21 (4), 753-756. doi: 10.1093/carcin/21.4.753

Hahn, M. E., Allan, L. L., and Sherr, D. H. (2009). Regulation of Constitutive and Inducible AHR Signaling: Complex Interactions Involving the AHR Repressor. Biochem. Pharmacol. 77 (4), 485-497. doi: 10.1016/ j.bcp.2008.09.016

Hooper, L. V., Midtvedt, T., and Gordon, J. I. (2002). How Host-Microbial Interactions Shape the Nutrient Environment of the Mammalian Intestine. Annu. Rev. Nutr. 22, 283-307. doi: 10.1146/annurev.nutr.22.011602.092259

Huang, E. H., Hynes, M. J., Zhang, T., Ginestier, C., Dontu, G., Appelman, H., et al. (2009). Aldehyde Dehydrogenase 1 is a Marker for Normal and Malignant Human Colonic Stem Cells (SC) and Tracks SC Overpopulation During Colon Tumorigenesis. Cancer Res. 69 (8), 3382-3389. doi: 10.1158/ 0008-5472.CAN-08-4418

Jans, C., and Boleij, A. (2018). The Road to Infection: Host-Microbe Interactions Defining the Pathogenicity of Streptococcus Bovis/Streptococcus Equinus Complex Members. Front. Microbiol. 9, 603. doi: 10.3389/fmicb.2018.00603

Jin, U. H., Cheng, Y., Park, H., Davidson, L. A., Callaway, E. S., Chapkin, R. S., et al. (2017). Short Chain Fatty Acids Enhance Aryl Hydrocarbon (Ah) Responsiveness in Mouse Colonocytes and Caco-2 Human Colon Cancer Cells. Sci. Rep. 7 (1), 10163. doi: 10.1038/s41598-017-10824-x

Kim, S., Dere, E., Burgoon, L. D., Chang, C. C., and Zacharewski, T. R. (2009). Comparative Analysis of AhR-Mediated TCDD-Elicited Gene Expression in Human Liver Adult Stem Cells. Toxicol. Sci. 112 (1), 229-244. doi: 10.1093/ toxsci/kfp189

Kim, S. H., Henry, E. C., Kim, D. K., Kim, Y. H., Shin, K. J., Han, M. S., et al. (2006). Novel Compound 2-Methyl-2H-Pyrazole-3-Carboxylic Acid (2Methyl-4-O-Tolylazo-Phenyl)-Amide (CH-223191) Prevents 2,3,7,8-TCDDInduced Toxicity by Antagonizing the Aryl Hydrocarbon Receptor. Mol. Pharmacol. 69 (6), 1871-1878. doi: 10.1124/mol.105.021832

Kumar, R., Herold, J. L., Schady, D., Davis, J., Kopetz, S., Martinez-Moczygemba, M., et al. (2017). Streptococcus Gallolyticus Subsp. Gallolyticus Promotes Colorectal Tumor Development. PloS Pathog. 13 (7), e1006440. doi: 10.1371/ journal.ppat.1006440

Kumar, R., Herold, J. L., Taylor, J., Xu, J., and Xu, Y. (2018). Variations Among Streptococcus Gallolyticus Subsp. Gallolyticus Strains in Connection With Colorectal Cancer. Sci. Rep. 8 (1), 1514. doi: 10.1038/s41598-018-19941-7

Lieberman, D. A., Weiss, D. G., Bond, J. H., Ahnen, D. J., Garewal, H., and Chejfec, G. (2000). Use of Colonoscopy to Screen Asymptomatic Adults for Colorectal Cancer. Veterans Affairs Cooperative Study Group 380. New Engl. J. Med. 343 (3), 162-168. doi: 10.1056/NEJM200007203430301

Matsuo, K., Ota, H., Akamatsu, T., Sugiyama, A., and Katsuyama, T. (1997). Histochemistry of the Surface Mucous Gel Layer of the Human Colon. Gut 40 (6), 782-789. doi: 10.1136/gut.40.6.782

McKay, J. A., Murray, G. I., Weaver, R. J., Ewen, S. W., Melvin, W. T., and Burke, M. D. (1993). Xenobiotic Metabolising Enzyme Expression in Colonic Neoplasia. Gut 34 (9), 1234-1239. doi: 10.1136/gut.34.9.1234

McMillan, B. J., and Bradfield, C. A. (2007). The Aryl Hydrocarbon Receptor Sans Xenobiotics: Endogenous Function in Genetic Model Systems. Mol. Pharmacol. 72 (3), 487-498. doi: 10.1124/mol.107.037259

Mercurio, M. G., Shiff, S. J., Galbraith, R. A., and Sassa, S. (1995). Expression of Cytochrome P450 mRNAs in the Colon and the Rectum in Normal Human Subjects. Biochem. Biophys. Res. Commun. 210 (2), 350-355. doi: 10.1006/ bbrc. 1995.1668

Metidji, A., Omenetti, S., Crotta, S., Li, Y., Nye, E., Ross, E., et al. (2018). The Environmental Sensor AHR Protects From Inflammatory Damage by Maintaining Intestinal Stem Cell Homeostasis and Barrier Integrity. Immunity 49 (2), 353-62 e5. doi: 10.1016/j.immuni.2018.07.010

Meunier, V., Bourrie, M., Berger, Y., and Fabre, G. (1995). The Human Intestinal Epithelial Cell Line Caco-2; Pharmacological and Pharmacokinetic Applications. Cell Biol. Toxicol. 11 (3-4), 187-194. doi: 10.1007/BF00756522

Nebert, D. W., and Dalton, T. P. (2006). The Role of Cytochrome P450 Enzymes in Endogenous Signalling Pathways and Environmental Carcinogenesis. Nat. Rev. 6 (12), 947-960. doi: 10.1038/nrc2015 
Nebert, D. W., and Karp, C. L. (2008). Endogenous Functions of the Aryl Hydrocarbon Receptor (AHR): Intersection of Cytochrome P450 1 (CYP1)Metabolized Eicosanoids and AHR Biology. J. Biol. Chem. 283 (52), 3606136065. doi: 10.1074/jbc.R800053200

Pasquereau-Kotula, E., Martins, M., Aymeric, L., and Dramsi, S. (2018). Significance of Streptococcus Gallolyticus Subsp. Gallolyticus Association With Colorectal Cancer. Front. Microbiol. 9, 614. doi: 10.3389/fmicb. 2018.00614

Pfaffl, M. W. (2001). A New Mathematical Model for Relative Quantification in Real-Time RT-PCR. Nucleic Acids Res. 29 (9), e45. doi: 10.1093/nar/29.9.e45

Pleguezuelos-Manzano, C., Puschhof, J., Rosendahl Huber, A., van Hoeck, A., Wood, H. M., Nomburg, J., et al. (2020). Mutational Signature in Colorectal Cancer Caused by Genotoxic Pks+ E. coli. Nature 580 (7802), 269-273. doi: 10.1038/s41586-020-2080-8

Poyart, C., Quesne, G., and Trieu-Cuot, P. (2002). Taxonomic Dissection of the Streptococcus Bovis Group by Analysis of Manganese-Dependent Superoxide Dismutase Gene (Soda) Sequences: Reclassification of 'Streptococcus Infantarius Subsp. Coli' as Streptococcus Lutetiensis Sp. Nov. And of Streptococcus Bovis Biotype 11.2 as Streptococcus Pasteurianus Sp. Nov. Int. J. Syst. Evol. Microbiol. 52 (Pt 4), 1247-1255. doi: 10.1099/00207713-52-4-1247

Rosenberg, D. W., and Leff, T. (1993). Regulation of Cytochrome P450 in Cultured Human Colonic Cells. Arch. Biochem. Biophys. 300 (1), 186-192. doi: 10.1006/ abbi.1993.1026

Rubinstein, M. R., Baik, J. E., Lagana, S. M., Han, R. P., Raab, W. J., Sahoo, D., et al. (2019). Fusobacterium Nucleatum Promotes Colorectal Cancer by Inducing Wnt/beta-Catenin Modulator Annexin A1. EMBO Rep. 20 (4), e47638. doi: $10.15252 / \mathrm{embr} .201847638$

Rusniok, C., Couve, E., Da Cunha, V., El Gana, R., Zidane, N., Bouchier, C., et al. (2010). Genome Sequence of Streptococcus Gallolyticus: Insights Into Its Adaptation to the Bovine Rumen and Its Ability to Cause Endocarditis. J. Bacteriol. 192 (8), 2266-2276. doi: 10.1128/JB.01659-09

Shimada, T., Yun, C. H., Yamazaki, H., Gautier, J. C., Beaune, P. H., and Guengerich, F. P. (1992). Characterization of Human Lung Microsomal Cytochrome P-450 $1 \mathrm{~A} 1$ and Its Role in the Oxidation of Chemical Carcinogens. Mol. Pharmacol. 41 (5), 856-864.

Spink, D. C., Katz, B. H., Hussain, M. M., Spink, B. C., Wu, S. J., Liu, N., et al. (2002). Induction of CYP1A1 and CYP1B1 in T-47D Human Breast Cancer Cells by Benzo[a]Pyrene is Diminished by Arsenite. Drug Metab. Dispos. 30 (3), 262-269. doi: 10.1124/dmd.30.3.262

Stecher, B., and Hardt, W. D. (2008). The Role of Microbiota in Infectious Disease. Trends Microbiol. 16 (3), 107-114. doi: 10.1016/j.tim.2007.12.008

Taddese, R., Garza, D. R., Ruiter, L. N., de Jonge, M. I., Belzer, C., Aalvink, S., et al. (2020). Growth Rate Alterations of Human Colorectal Cancer Cells by 157 Gut Bacteria. Gut Microbes 12 (1), 1-20. doi: 10.1080/19490976.2020.1799733

Towbin, H., Staehelin, T., and Gordon, J. (1979). Electrophoretic Transfer of Proteins From Polyacrylamide Gels to Nitrocellulose Sheets: Procedure and Some Applications. Proc. Natl. Acad. Sci. U. S. A. 76 (9), 4350-4354. doi: 10.1073/pnas.76.9.4350
Tripodi, M. F., Fortunato, R., Utili, R., Triassi, M., and Zarrilli, R. (2005). Molecular Epidemiology of Streptococcus Bovis Causing Endocarditis and Bacteraemia in Italian Patients. Clin. Microbiol. Infect. 11 (10), 814-819. doi: 10.1111/j.1469-0691.2005.01248.x

Viljoen, K. S., Dakshinamurthy, A., Goldberg, P., and Blackburn, J. M. (2015). Quantitative Profiling of Colorectal Cancer-Associated Bacteria Reveals Associations Between Fusobacterium Spp., Enterotoxigenic Bacteroides Fragilis (ETBF) and Clinicopathological Features of Colorectal Cancer. PloS One 10 (3), e0119462. doi: 10.1371/journal.pone.0119462

Vollaard, E. J., and Clasener, H. A. (1994). Colonization Resistance. Antimicrob. Agents Chemother. 38 (3), 409-414. doi: 10.1128/AAC.38.3.409

Wang, X., Allen, T. D., May, R. J., Lightfoot, S., Houchen, C. W., and Huycke, M. M. (2008). Enterococcus Faecalis Induces Aneuploidy and Tetraploidy in Colonic Epithelial Cells Through a Bystander Effect. Cancer Res. 68 (23), 9909-9917. doi: 10.1158/0008-5472.CAN-08-1551

Wu, S., Rhee, K. J., Albesiano, E., Rabizadeh, S., Wu, X., Yen, H. R., et al. (2009). A Human Colonic Commensal Promotes Colon Tumorigenesis via Activation of T Helper Type 17 T Cell Responses. Nat. Med. 15 (9), 1016-1022. doi: 10.1038/ nm.2015

Yu, L. J., Matias, J., Scudiero, D. A., Hite, K. M., Monks, A., Sausville, E. A., et al. (2001). P450 Enzyme Expression Patterns in the NCI Human Tumor Cell Line Panel. Drug Metab. Dispos. 29 (3), 304-312.

Yu, M., Wang, Q., Ma, Y., Li, L., Yu, K., Zhang, Z., et al. (2018). Aryl Hydrocarbon Receptor Activation Modulates Intestinal Epithelial Barrier Function by Maintaining Tight Junction Integrity. Int. J. Biol. Sci. 14 (1), 69-77. doi: 10.7150/ijbs.22259

Zudaire, E., Cuesta, N., Murty, V., Woodson, K., Adams, L., Gonzalez, N., et al. (2008). The Aryl Hydrocarbon Receptor Repressor Is a Putative Tumor Suppressor Gene in Multiple Human Cancers. J. Clin. Invest. 118 (2), 640650. doi: 10.1172/JCI30024

Conflict of Interest: The authors declare that the research was conducted in the absence of any commercial or financial relationships that could be construed as a potential conflict of interest.

Publisher's Note: All claims expressed in this article are solely those of the authors and do not necessarily represent those of their affiliated organizations, or those of the publisher, the editors and the reviewers. Any product that may be evaluated in this article, or claim that may be made by its manufacturer, is not guaranteed or endorsed by the publisher.

Copyright (c) 2021 Taddese, Roelofs, Draper, Wu, Wu, Swinkels, Tjalsma and Boleij. This is an open-access article distributed under the terms of the Creative Commons Attribution License (CC BY). The use, distribution or reproduction in other forums is permitted, provided the original author(s) and the copyright owner(s) are credited and that the original publication in this journal is cited, in accordance with accepted academic practice. No use, distribution or reproduction is permitted which does not comply with these terms. 